OPEN ACCESS

Edited by:

Antonio Gambardella, University of Catanzaro, Italy

Reviewed by: Albert Giralt,

University of Barcelona, Spain

Amit U. Joshi,

Stanford University, United States

${ }^{*}$ Correspondence:

Xavier Xifró

xavier.xifro@udg.edu

Specialty section:

This article was submitted to Cellular Neuropathology, a section of the journal Frontiers in

Cellular Neuroscience

Received: 29 January 2020 Accepted: 22 June 2020 Published: 17 July 2020

Citation: Solés-Tarrés I, Cabezas-Llobet N, Vaudry $D$ and Xifró $X$ (2020) Protective Effects of Pituitary Adenylate Cyclase-Activating Polypeptide and Vasoactive Intestinal Peptide Against Cognitive Decline in Neurodegenerative Diseases. Front. Cell. Neurosci. 14:221. doi: 10.3389/fncel.2020.00221

\section{Protective Effects of Pituitary Adenylate Cyclase-Activating Polypeptide and Vasoactive Intestinal Peptide Against Cognitive Decline in Neurodegenerative Diseases}

\author{
Irene Solés-Tarrés ${ }^{1}$, Núria Cabezas-Llobet ${ }^{1}$, David Vaudry $^{2}$ and Xavier Xifró ${ }^{1 *}$ \\ ${ }^{1}$ New Therapeutic Targets Group (TargetsLab), Department of Medical Science, Faculty of Medicine, Universitat de Girona, \\ Girona, Spain, ${ }^{2}$ Laboratory of Neuronal and Neuroendocrine Communication and Differentiation, Neuropeptides, Neuronal \\ Death and Cell Plasticity Team, Normandie University, UNIROUEN, Inserm, Rouen, France
}

Cognitive impairment is one of the major symptoms in most neurodegenerative disorders such as Alzheimer's (AD), Parkinson (PD), and Huntington diseases (HD), affecting millions of people worldwide. Unfortunately, there is no treatment to cure or prevent the progression of those diseases. Cognitive impairment has been related to neuronal cell death and/or synaptic plasticity alteration in important brain regions, such as the cerebral cortex, substantia nigra, striatum, and hippocampus. Therefore, compounds that can act to protect the neuronal loss and/or to reestablish the synaptic activity are needed to prevent cognitive decline in neurodegenerative diseases. Pituitary adenylate cyclaseactivating polypeptide (PACAP) and vasoactive intestinal peptide (VIP) are two highly related multifunctional neuropeptides widely distributed in the central nervous system (CNS). PACAP and VIP exert their action through two common receptors, VPAC1 and VPAC2, while PACAP has an additional specific receptor, PAC1. In this review article, we first presented evidence showing the therapeutic potential of PACAP and VIP to fight the cognitive decline observed in models of $A D, P D$, and $H D$. We also reviewed the main transduction pathways activated by PACAP and VIP receptors to reduce cognitive dysfunction. Furthermore, we identified the therapeutic targets of PACAP and VIP, and finally, we evaluated different novel synthetic PACAP and VIP analogs as promising pharmacological tools.

Keywords: Alzheimer's disease, Parkinson's disease, Huntington's disease, cognition, synaptic plasticity, PAC1, VPAC1, VPAC2

\section{INTRODUCTION}

Cognition is the result of the formation of functional neuronal circuits in many cerebral areas governed by a dynamic phenomenon named synaptic plasticity. People suffering from neurodegenerative diseases commonly present cognitive impairment, such as dementia, deficits in learning and attention, or incomplete executive function among others, affecting the 
daily life of patients and their families. This impairment is mediated by the extracellular or intracellular accumulation of protein aggregates that disrupt synaptic plasticity leading to neuronal dysfunction and/or neuronal death. Several mechanisms have been involved in neuronal plasticity disturbance and neuronal cell death, such as inflammation, excitotoxicity, oxidative stress, and neurotrophic deprivation. These mechanisms affect genetic expression through the activation/inhibition of some pathways and transcription factors. The result of altered genetic expression is the disruption of structural and functional synaptic plasticity and/or the viability of neurons. Thus, molecules able to promote synaptic plasticity or neuronal viability by the interaction and inhibition of these mechanisms in brain areas related to learning and memory could be interesting therapeutic compounds to stop the cognitive decline in neurodegenerative diseases.

Pituitary adenylate cyclase-activating polypeptide (PACAP) and vasoactive intestinal polypeptide (VIP) are well-known neuropeptides that exert a potent neuroprotective effect through the activation of different signaling pathways and transcriptional-genetic activity (Dejda et al., 2005; Vaudry et al., 2009). Some data in animal models show that the lack of PACAP and VIP is associated with a cognitive decline. Indeed, PACAP deficient mice display impaired recognition memory (Shibasaki et al., 2015) and VIP deficient mice exhibit cognitive deficits (Chaudhury et al., 2008). Recently, it has been shown that VIP positive interneurons in the CA1 hippocampal area are necessary for spatial learning (Turi et al., 2019). Interestingly, in rat hippocampal slices, it has been observed that PACAP and VIP exert a direct effect in synaptic transmission (Ciranna and Cavallaro, 2003). This context and the capacity of PACAP and VIP to cross the blood-brain barrier suggest that these neuropeptides and their receptors-mediated signaling could have promising therapeutic activity in neurodegenerative diseases. In this review, we summarize the pieces of evidence showing that PACAP and VIP administration help to preserve cognitive function in different preclinical models of Alzheimer's disease (AD), Parkinson's disease (PD) and Huntington's disease (HD). We also identify the main molecular mechanisms by which PACAP and VIP promote neuronal survival and synaptic plasticity in neurons to preserve cognitive performances. Finally, we review novel VIP and PACAP synthetic derivatives which could represent promising therapeutic tools for the treatment of neurodegenerative diseases.

\section{PACAP AND VIP PROMOTE COGNITIVE FUNCTION IN NEURODEGENERATIVE DISEASE MODELS}

\section{Alzheimer's Disease}

Alzheimer's disease is the most common form of dementia characterized by the irreversible deterioration of cognitive function (Alzheimer's Association, 2015) associated with the accumulation of amyloid- $\beta$ (A $\beta$ ) plaques and neurofibrillary tangles in the cognitive brain areas (Hou et al., 2019).
The potential of PACAP as a therapeutic agent in $\mathrm{AD}$ neuropathology has been studied for many years in different experimental models (Table 1). In vitro studies have reported that PACAP protects against $\mathrm{A} \beta$-mediated toxicity (Onoue et al., 2002; Han et al., 2014b). This neuroprotective effect of PACAP is associated with an improvement of the cognitive function in $\mathrm{AD}$ mice models. A long-term daily intranasal PACAP administration ameliorates the performance in the novel object recognition test in the $\mathrm{AD}$ transgenic mice model overexpressing the amyloid precursor protein (APP; Rat et al., 2011). In these animals, the rescue of memory deficits was linked with an increase of brain-derived neurotrophic factor (BDNF) and the enhancement of the non-amyloidogenic pathway of APP (Rat et al., 2011). Also, PACAP reduced the inflammatory response (Rat et al., 2011). Thus, PACAP is suggested to prevent cognitive decline in $\mathrm{AD}$ exerting neurotrophic, neuroprotective, and anti-inflammatory effects. Interestingly, the capacity of PACAP to counteract cognitive decline was also proved in SAMP8 mice, another AD model expressing the $\mathrm{A} \beta$ (Nonaka et al., 2012). In this study, PACAP alone or together with cyclodextrins was given by intranasal administration. PACAP was found in all brain regions, but some regions such as the occipital cortex and striatum incorporated much more PACAP than others. This pattern of distribution of the labeled PACAP is different from the one found when the peptide is given by intravenous injection, in which the highest uptakes are found in the hippocampus and hypothalamus (Nonaka et al., 2002). The addition of cyclodextrins can increase or decrease the uptake of PACAP in different brain regions depending on the cyclodextrin used. Such treatment could thus be used to promote neuropeptide uptake toward specific brain regions and was shown to improve the learning memory of SAMP8 mice in the T-maze task (Dogrukol-Ak et al., 2009). Because of these promising results, it was proposed that the downregulation of PACAP may be involved in AD neuropathology. Indeed, a comparative analysis of gene expression showed decreased protein levels of PACAP and BDNF in three different models of $\mathrm{AD}$ with $\mathrm{A} \beta$ deposition (Wu et al., 2006). Years later, PACAP expression was found decreased and inversely correlated with $A \beta$ and Tau protein levels in a triple transgenic mouse model of AD (3xTG, Psen1/APPSwe/TauP301L; Han et al., 2014b). According to these findings, studies with AD patients demonstrated that PACAP levels were reduced in cortical areas such as the entorhinal cortex, the middle temporal gyrus, the superior frontal gyrus, and the primary visual cortex (Han et al., 2014a). Interestingly, PACAP deficits in humans were associated with clinical severity of AD (Han et al., 2015) and inversely correlated with $\mathrm{A} \beta$ plaques and neurofibrillary tangles (Han et al., 2014b). Altogether, these results point out that reduced levels of PACAP may contribute to the pathological process of $\mathrm{AD}$ and could have an important implication in the cognitive decline.

Different studies using animals and cell culture models of $\mathrm{AD}$ have revealed that VIP also acts as a neuroprotective agent against the pathogenesis of this disorder (Table 1). A recent study using $5 \mathrm{XFAD}$ mice, an $\mathrm{AD}$ model with massive cerebral $\mathrm{A} \beta$ deposits, shows that VIP intraperitoneal chronic 
TABLE 1 | Beneficial effects of pituitary adenylate cyclase-activating polypeptide (PACAP) and vasoactive intestinal peptide (VIP) in cellular and animal models of different neurodegenerative diseases.

\begin{tabular}{|c|c|c|c|}
\hline & & PACAP & VIP \\
\hline \multirow[t]{2}{*}{ Alzheimer's disease } & \multirow[t]{2}{*}{ Animal model } & \multirow{2}{*}{$\begin{array}{l}\text { Improves performance in the novel object } \\
\text { recognition test in APP[V717l]-transgenic mice } \\
\text { (Rat et al., 2011). } \\
\text { Improves learning in T-maze task in } \\
\text { SAMP8 mice (Dogrukol-Ak et al., 2009). }\end{array}$} & $\begin{array}{l}\text { Decreases } A \beta \text { accumulation and } \\
\text { atrophy in the hippocampus and cortex } \\
\text { in 5XFAD mice (Korkmaz et al., 2019). }\end{array}$ \\
\hline & & & $\begin{array}{l}\text { Reduces inflammation and attenuates } \\
\text { amyloidosis in the hippocampus in } \\
\text { PS1/APP transgenic mice } \\
\text { (Song et al., 2012). } \\
\text { Ameliorates the cognitive performance } \\
\text { in the water maze test in ApoE mice } \\
\text { (superactive VIP derivate; } \\
\text { Gozes et al., 1997). }\end{array}$ \\
\hline
\end{tabular}

Cellular model $\quad$ Protects against $A \beta$-mediated toxicity in PC12 cells (Onoue et al., 2002) and primary neuronal cell culture (Han et al., 2014b).

Cellular model
Parkinson's disease

Animal model

Cellular model

Animal model

Improves learning and memory in three different paradigms of water-maze task in MPTP-injected mice (Deguil et al., 2010).

Prevents from motor and behaviour deficits in 6-OHA lesioned rats (Reglodi et al., 2004a,b).

Improves locomotor function and behaviour alterations in rotenone-induced snails (Maasz et al., 2017).

Protects against 6-OHDA (Takei et al., 1998), MPTP (Chung et al., 2005), rotenone (Wang et al., 2005), salsolino (Brown et al., 2013) and paraquat (Hajji et al., 2019).

Huntington's disease
Reduces the loss of striatal neurons and attenuates behavioural disturbances in striatum-lesioned mice by quinolonic acid injection (Tamás et al., 2006).

Improves the performance in the novel object recognition test and the T-maze spontaneous alternation task in R6/1 transgenic mice (Cabezas-Llobet et al., 2018).

Induces neuritic branching in $\mathrm{R} 6 / 1$ hippocampal primary culture (Cabezas-Llobet et al., 2018). administration significantly decreases $A \beta$ accumulation and reduces the atrophy in brain regions involved in cognition, such as hippocampus and cortex (Korkmaz et al., 2019). Importantly, VIP protection against $A \beta$-induced cell death was also observed in experiments using PC12 cells and cortical cell cultures (Gozes et al., 1996; Onoue et al., 2002). However, the survival effect of VIP against $A \beta$-induced cell death seems to be less effective than PACAP protective activity. This result could be due to the growing evidence that the neuroprotective effect of VIP is mainly through its action on microglial cells. In microglia/neuron cocultures, some studies showed that the presence of VIP protects from $A \beta$-induced neurodegeneration, inhibiting the secretion of pro-inflammatory interleukins and neurotoxic agents from microglia and inducing $\mathrm{A} \beta$ phagocytosis (Delgado et al., 2008; Song et al., 2012). Interestingly, both immunosuppressive and anti-amyloidosis effects of VIP have been confirmed in vivo. Constitutive overexpression of VIP in the hippocampus reduces inflammation and attenuates amyloidosis in transgenic PS1/APP mice, which present increased $\beta$-amyloid production associated with behavioral abnormalities (Song et al., 2012). Inflammatory reactions and microglia activation are well known to contribute to neuronal degeneration and to be associated with dementia 
in $\mathrm{AD}$. Therefore, neuroprotective and immunomodulatory capacities of VIP make this neuropeptide an attractive candidate for the treatment of cognitive deficits in $\mathrm{AD}$. However, the implication of VIP expression in AD pathology is still unclear. A study using human samples did not show any differences in VIP expression in different cognitive-related regions such as the hippocampus, amygdala, thalamus, and striatum of patients with AD (Ferrier et al., 1983). In contrast, a significant reduction of VIP immunoreactivity was found in the cerebral cortex of $\mathrm{AD}$ patients (Arai et al., 1984). In AD animal models, the role of VIP in the neuropathology has been poorly studied. Only in the $\mathrm{AD}$ mice model deficient in apolipoprotein $\mathrm{E}$ (ApoE), a reduction in VIP transcription was reported (Gozes et al., 1997). Interestingly, chronic intranasal administration of a superactive VIP agonist ameliorates the learning and memory deficits of these animals in water maze test (Gozes et al., 1997), suggesting that the peptide could at least be of therapeutical interest for the treatment of the disease.

\section{Parkinson's Disease}

Parkinson's disease is the second most common neurodegenerative disorder after AD (Kalia and Lang, 2015). $\mathrm{PD}$ neuropathology is characterized by the degeneration of dopaminergic neurons in the substantia nigra pars compacta (SNc) and the subsequent loss of their projections to the striatum (Bezard et al., 2003). Although PD has long been characterized by motor disturbances, cognitive dysfunction is common in patients and can range from mild impairment to dementia (Caviness et al., 2007). Nowadays, the relationship between the neurodegenerative process and cognitive decline in $\mathrm{PD}$ remains unclear. While some authors point out a frontal lobe dysfunction because of the affection in the mesocortical dopaminergic system, others suggest a deficit in the cortico-basal ganglia circuit due to the nigrostriatal dopaminergic degeneration (Sawamoto et al., 2007). Besides, some clinical studies indicate that hippocampus atrophy could also contribute to memory impairment in $\mathrm{PD}$ (Brück et al., 2004).

The neuroprotective action of PACAP in PD has been well-established in both in vitro and in vivo models (Table 1, Reglodi et al., 2017, 2018). PACAP has proved to be neuroprotective in different cell cultures and explant models of PD, using 6-hydroxydopamine (OHDA), 1-Methyl-4-phenyl1,2,3,6-tetrahydropyridine (MPTP), rotenone, salsolinol and paraquat neurotoxic agents (Takei et al., 1998; Chung et al., 2005; Wang et al., 2005; Brown et al., 2013; Lamine-Ajili et al., 2016; Hajji et al., 2019). These in vitro results are in line with findings observed in animal models, which have demonstrated the therapeutic action of PACAP in motor and behavioral disturbances of PD (Reglodi et al., 2004a,b; Maasz et al., 2017). The capacity of PACAP to prevent the cognitive impairment in PD was showed using three specific cognitive processes in an MPTP mouse model: habit learning, working memory, and spatial reference in learning and memory, which depend on the integrity of the striatum, frontal cortex, and hippocampus, respectively. PACAP could improve learning and memory functions in those three different paradigms (Deguil et al., 2010). Hence, the authors suggest that PACAP could not only restore the dopaminergic neurotransmission but also the hippocampal cholinergic transmission, as other authors had seen before (Masuo et al., 1993; Wang et al., 2008; Maasz et al., 2017). The fact that PACAP was able to protect the three neuronal cell types makes it a promising therapeutic agent to fight against cognitive decline in PD. Also, recent results obtained in different animal models of PD showed the dysregulation of PACAP and its receptors in brain areas related to cognition. A specific reduction of PAC1 receptor was reported in the basal ganglia of MPTP-induced parkinsonian macaques (Feher et al., 2018). Likewise, PACAP-knockout mice were shown to be more vulnerable to paraquat (a pesticide that increases the risk of PD) than wild-type (Watson et al., 2013). However, there are no studies relating to a decrease of PACAP or PAC1 receptor level with impairment of cognitive functions in PD. Therefore, further research is needed to establish if endogenous PACAP and its receptors are involved in the progression of $\mathrm{PD}$, and specifically in cognitive symptoms.

In different PD neuronal and animal models, VIP has proved to protect either directly or indirectly (Table 1, Korkmaz and Tunçel, 2019). VIP was found to protect directly against dopamine and 6-OHDA toxicity in PC12 and neuroblastoma cells (Offen et al., 2000). VIP also exerted a direct effect preventing neurons from oxidative stress and apoptosis in a 6-OHDA murine model (Tunçel et al., 2012). Moreover, VIP was found to enhance the spine density and act as a neurotrophic factor in the striatum of parkinsonian rats (Korkmaz et al., 2012; Yelkenli et al., 2016). VIP could also indirectly exert protection through the suppression of both microglial activation and astrogliosis in PD (Delgado and Ganea, 2003; Yelkenli et al., 2016). Besides this, some authors support that VIP neuroprotective effect is probably mediated by masts cells, suggesting a VIP immunomodulatory action (Tunćel et al., 2005). Also, VIP was found to reverse the rotational deficits in a 6-OHDA rat model of PD (Tunćel et al., 2005), indicating a potential therapeutic activity. Unfortunately, no studies have been conducted regarding the specific effect on animals' cognitive function. Moreover, in contrast to PACAP, there is no evidence that VIP participates in PD neuropathology. VIP levels were found unaltered in the brains of both demented and non-demented parkinsonian patients (Jégou et al., 1988).

\section{Huntington's Disease}

Huntington's disease is a hereditary autosomal neurodegenerative disorder characterized by cognitive, psychiatric, and motor dysfunction. The genetic cause of HD is an abnormal expansion of CAG in the gene encoding for the protein huntingtin (htt; MacDonald et al., 1993). The resulting mutant htt (mhtt) protein causes a severe degeneration of striatal neurons that leads to motor disabilities. Also, mhtt promotes synaptic dysfunction in some cortical and hippocampal neuronal populations, which has been associated with the cognitive decline in HD (Giralt et al., 2012). 
There are only two studies that explore the therapeutic potential of PACAP in the treatment of HD (Table 1). However, the results are promising. First, the effect of PACAP was studied in an excitotoxic model of HD. In HD-induced rats, PACAP treatment reduces the loss of striatal neurons and attenuates behavioral disturbances (Tamás et al., 2006). Years later, a second study found that PACAP can counteract the hippocampal-dependent cognitive decline in a transgenic HD mouse model by the analysis of novel object recognition test and the T-maze spontaneous alternation task (Cabezas-Llobet et al., 2018). This cognitive improvement is associated with an increased expression of proteins related to synaptic plasticity, such as BDNF, and the recovery of synaptic particles in the hippocampus. Moreover, in HD hippocampal primary cultures, PACAP treatment increases the number and length of neurites (Cabezas-Llobet et al., 2018). Thus, PACAP is suggested to improve the cognitive function by enhancing synaptic plasticity in the hippocampus. Interestingly, PACAP treatment also restores the PAC1 receptor protein level, which is altered in the hippocampus of $\mathrm{HD}$ mice from the onset of cognitive decline. Therefore, the beneficial effects of PACAP are suggested to be through the stimulation of the PAC1 receptor (Cabezas-Llobet et al., 2018).

Very few authors have studied the possible role of VIP in HD pathology. The first study regarding VIP and HD, showed no changes in VIP protein levels in the frontal cortex and basal ganglia in human HD post-mortem samples (Emson et al., 1979). However, some other studies indicate that VIP expression is altered in brain areas related to non-motor symptoms in HD. A post-mortem analysis of HD patients revealed a reduction of VIP immunoreactivity in the central nucleus of the amygdala (Zech et al., 1986). Recently, a decreased expression of VIP receptors was also found in the hippocampus of a transgenic HD mouse model (Cabezas-Llobet et al., 2018). Therefore, the impaired VIPergic signaling found in these regions could be involved in neuropathology which leads to cognitive and neuropsychiatric symptoms in HD (Fahrenkrug et al., 2007). Unfortunately, there are no other references regarding the relationship between VIP and non-motor disturbances in HD, and no information concerning the VIP therapeutic potential on the symptomatology.

\section{Amyotrophic Lateral Sclerosis and Multiple Sclerosis}

Amyotrophic lateral sclerosis (ALS) and multiple sclerosis (MS) are two diseases that affect both the brain and spinal cord nervous tissue. ALS is marked by progressive degeneration of upper and lower motor neurons while MS is characterized by demyelination due to an autoimmune response. Although ALS and MS have been traditionally viewed as diseases of the motor system, cognitive impairment also occurs in these pathologies (Chiaravalloti and DeLuca, 2008; Benbrika et al., 2019). It has been suggested that VIP and PACAP may contribute to ALS and MS non-motor symptomatology (Staines, 2008). In ALS patients, VIP levels were found decreased in cerebrospinal fluid (CSF) while PACAP and PAC1 receptor had an altered expression in the motor cortex (Werdelin et al., 1989; Bonaventura et al., 2018). Similarly, in MS patients VIP and PACAP CSF levels are significantly diminished (Andersen et al., 1984; BaranowskaBik et al., 2013). In animals, it has been shown that a synthetic modified analog of VIP exerts an anti-inflammatory effect improving motor function and increasing life-span in a ALS rat model (Goursaud et al., 2015). In an MS-related mouse model, PACAP ameliorated both clinical and pathologic manifestations of experimental autoimmune encephalomyelitis (EAE), while treatment with VIP reduced incidence and severity of EAE by an anti-inflammatory action (Kato et al., 2004; Fernandez-Martin et al., 2006). Moreover, PACAP deficient mice exhibited exacerbated EAE, a phenotype associated with increased inflammatory response, suggesting a protective role of the endogenous source of this neuropeptide in the disease (Tan et al., 2009, 2013). Unfortunately, no studies are exploring the capacity of PACAP and VIP to fight the cognitive decline in ALS and MS.

\section{MECHANISMS OF ACTION: FROM RECEPTOR (PAC1, VPAC1 AND VPAC2) ACTIVATION TO MOLECULAR MECHANISMS}

\section{PACAP/VIP Receptors and Its Distribution in the Central Nervous System}

The beneficial effects of PACAP and VIP on cognitive disturbances that occur in neurodegenerative diseases are due to the expression of their receptors in affected brain areas. PACAP has a high and specific affinity for the PAC1 receptor (PAC1R; Harmar et al., 2012). Additionally, PACAP and VIP share two receptors: VPAC1 receptor (VPAC1R) and VPAC2 receptor (VPAC2R), thanks to their high homology of structure ( $68 \%$ amino acid identity).

PAC1R is much more expressed in the whole Central Nervous System (CNS) than VPAC1R and VPAC2R transcripts (Basille et al., 2000; Jolivel et al., 2009). The dentate gyrus of the hippocampus, the supraoptic nucleus of the hypothalamus, cerebral cortex, and olfactory bulb are regions where PAC1R is most highly expressed (Hashimoto et al., 1996; Nomura et al., 1996; Zhou et al., 2000). PAC1R mRNA high expression levels are also present in cingulate, entorhinal and piriform cortices; pyramidal and nonpyramidal cells of the hippocampal formation; amygdaloid nuclei; centromedial, mediodorsal, and ventromedial nuclei of the thalamus; hypothalamus; nucleus accumbens; superior colliculus, central gray and SNc; pontine raphe nuclei and cerebellum (Figure 1; Hashimoto et al., 1996; Shioda et al., 1996; Zhou et al., 2000). Concerning VPAC1R and VPAC2R, studies indicate a different but complementary distribution of their mRNA localization throughout the brain. VPAC1R is expressed in the hippocampus and the cerebral cortex, while VPAC2R highest expression is found in the thalamus, the hypothalamus, the hippocampus, the amygdala and the pontine nuclei (Figure 1; Vaudry et al., 2009). Both VPAC receptors have low expression in the olfactory bulb (Figure 1). In the cerebral cortex, VPAC1R is abundant in layers 
III and V, while on the other hand, VPAC2R is rather localized in layer VI (Usdin et al., 1994). Importantly, despite the distinctive mRNA distribution, protein expression of PAC1R, VPAC1R, and/or VPAC2R have been found in all cognition-related regions (Joo et al., 2004).

As all three receptors belong to the superfamily of $G$ proteincoupled receptors, the beneficial effects of PACAP and VIP are associated to the activation of their related signaling second messengers: cAMP/adenylyl cyclase (AC)/protein kinase A (PKA), phospholipase (PLC)/protein kinase C (PKC), mitogenactivated protein kinase (MAPK) and phosphatidylinositol 3 kinase (PI3K)/Akt transduction pathways (Dickson and Finlayson, 2009; Vaudry et al., 2009). Expression and activity dysregulation of these proteins and related signaling mechanisms are involved in cognitive disturbances that occur in neurodegenerative diseases. Thus, the activation of these pathways and their related transcriptional machinery in brain areas related to learning and memory function has been proposed to favor the cognitive functions by promoting neuronal viability or synaptic plasticity (Giralt et al., 2012; Rai et al., 2019; Ureshino et al., 2019). Importantly, the actions of PACAP and VIP among these proteins can be direct or indirect, as receptors are not only present in neurons but are also expressed in glial cells (Ashur-Fabian et al., 1997; Grimaldi and Cavallaro, 1999).

\section{The anti-Apoptotic and Neurotrophic Functions of PAC1R}

\section{PAC1 Receptor in Anti-apoptotic Signaling}

The antiapoptotic effects of PACAP in neurons are mainly mediated through PAC1R that activates pathways and genes downregulated in cognitive brain areas of neurodegenerative diseases. In immature cerebellar granule neurons, PACAPPAC1R stimulation protects against many pro-apoptotic insults such as hydrogen peroxide, ethanol, and C2-ceramide (Vaudry et al., 2002b,c; Falluel-Morel et al., 2004; Aubert et al., 2006). This effect is associated with the AC/PKA pathway and phosphorylation of the extracellular signal-regulated kinase (ERK). Hence, PACAP action is blocked by PKA or MAPK inhibitors and mimicked by raising cAMP levels (Vaudry et al., 1998, 2000b; Falluel-Morel et al., 2004). Also, PAC1R activation promotes the transcription of the immediate-early gene c-fos, which induces B-cell lymphoma 2 (Bcl-2) expression. In the mitochondria, $\mathrm{Bcl}-2$ blocks the cytochrome $\mathrm{c}$ release into the cytosol, preventing caspase-3 activation (Falluel-Morel et al., 2004; Aubert et al., 2006). Inhibition of mitochondrial apoptotic pathway by PACAP-PAC1R stimulation has been demonstrated in vivo using an $\mathrm{AD}$ mouse model overexpressing the APP. In these animals, PACAP intranasal administration increases both PACAP and PAC1R mRNA expression as well as the Bcl-2 protein levels (Rat et al., 2011). In addition to these findings, in vitro studies have demonstrated PACAP protective effect against $\mathrm{A} \beta$-mediated toxicity via the inhibition of caspase- 3 activity in PC12 cells (Onoue et al., 2002) or via the enhancement of the mitochondrial function in primary neuronal cell culture (Han et al., 2014b).
Interestingly, in PC12 cells, it has been shown that PACAPPAC1R activation also protects against rotenone-induced apoptosis, a PD cellular model, through a mitochondrialindependent pathway (Wang et al., 2005). Importantly, the molecular mechanisms involve the activation of MAPK by PKA leading to the inhibition of caspase-3 activity (Wang et al., 2005). PACAP also activates various genes through the PKA pathway (Vaudry et al., 2002a), some of which such as peroxiredoxin 2 (Botia et al., 2008), tissue plasminogen activator (tPA; Raoult et al., 2011), stathmin (Dejda et al., 2010) and Serpin bla (Seaborn et al., 2014), being involved in its neuroprotective effect.

Besides AC/PKA and MAPK, some other pathways are suggested to be involved in the PAC1R-mediated anti-apoptotic action. For instance, PAC1R stimulation has demonstrated to prevent cerebellar granule neurons from caspase-3 activation via PKC transduction pathway (Vaudry et al., 2000a). In olfactory neurons, PAC1R also inhibits apoptosis via activation of the PLC (Han and Lucero, 2006). Moreover, PACAP protects against $\mathrm{KCl}$-induced apoptosis of cerebellar granule neurons by the activation of the PI3K/Akt pathway (Bhave and Hoffman, 2003). In conclusion, PAC1R acts via different but sometimes complementary signaling pathways to block neuronal apoptosis mainly through the inhibition of caspase-3 activity (Seaborn et al., 2011; Figure 2). However, more data are needed to associate the activation of these pathways with the PACAP-mediated cognitive enhancement, especially since besides its direct neuroprotective effect, PACAP may act indirectly on neuronal survival via activation of PAC1R expressed by astrocytes. Indeed, PACAP stimulates endozepine release from cultured astrocytes via a PAC1R/PKA pathway (Masmoudi et al., 2003) and intracerebroventricular injection of the endozepine octadecaneuropeptide (ODN) prevents the degeneration of dopaminergic neurons in an in vivo model of PD (Bahdoudi et al., 2018). Interestingly ODN protects neurons from apoptosis through inhibition of the oxidative stress (Kaddour et al., 2013), which is often responsible for cell death in neurodegenerative diseases (Niedzielska et al., 2016).

\section{PAC1 Receptor in Neurotrophic Signaling}

PACAP/PAC1R stimulation has been found to enhance the expression of neurotrophins and related receptors in neuronal cells, promoting survival, synaptic plasticity, proliferation, and/or differentiation. Several in vitro and in vivo studies have shown that PAC1R stimulation can increase BDNF transcription and expression. BDNF is a key regulator of the maintenance of neuronal populations in the CNS and plays an important role in synaptic plasticity and synaptogenesis (Bramham and Messaoudi, 2005; Cohen-Cory et al., 2010; Bathina and Das, 2015). It has been demonstrated that BDNF protein level is positively correlated with the number of dendritic spines in the dentate granular neurons of mice (Stranahan, 2011). Importantly, BDNF expression is downregulated in many neurodegenerative diseases (Bathina and Das, 2015). It has also been shown a reduced expression of BDNF in PAC1R deficient-mice (Zink et al., 2004). Moreover, 


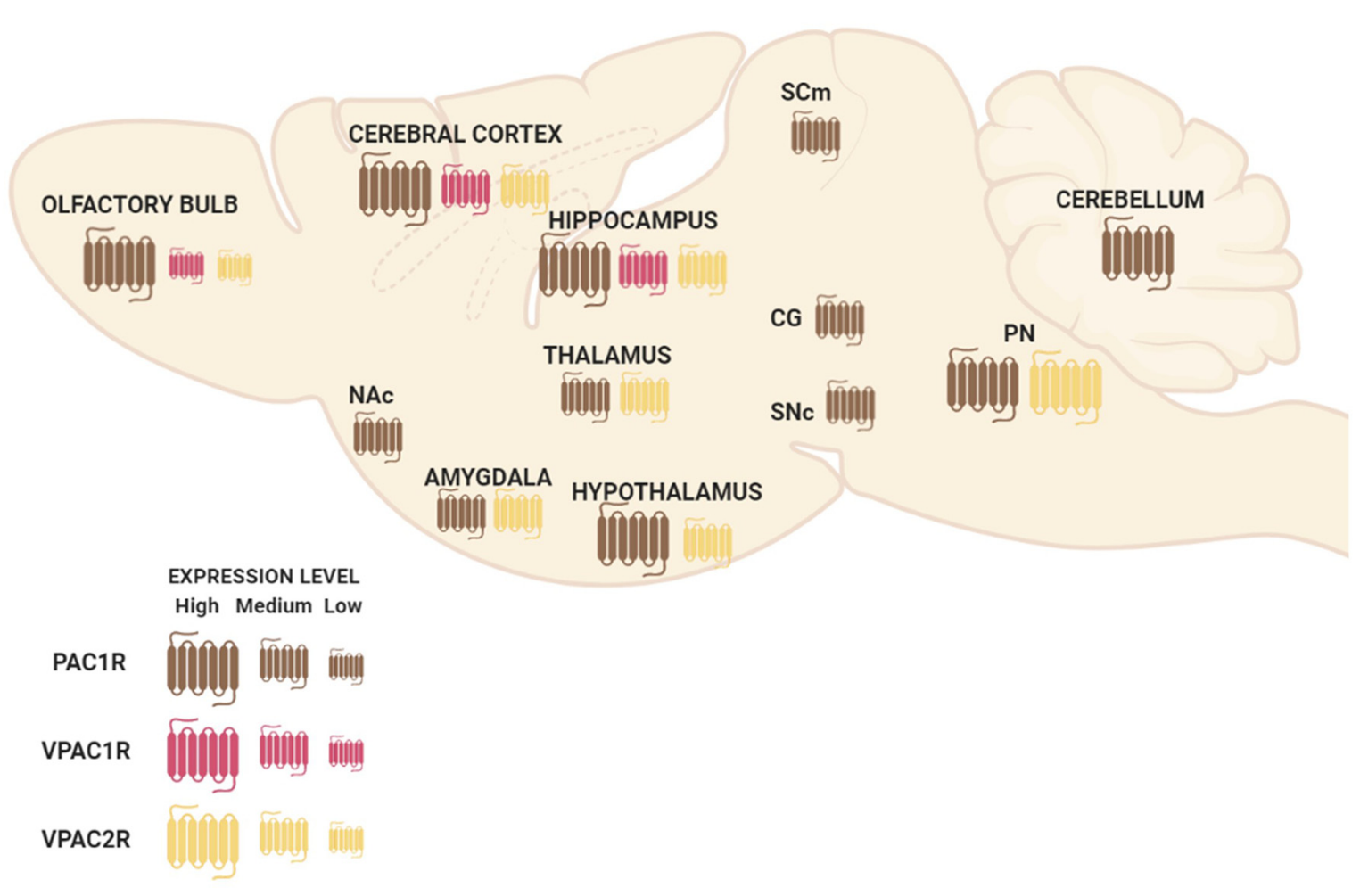

FIGURE 1 | Schematic representation of pituitary adenylate cyclase-activating polypeptide (PACAP) and vasoactive intestinal peptide (VIP) receptors' mRNA distribution in a sagittal view of the mouse brain. Abbreviations: Nac, nucleus accumbens; SCm, superior colliculus; CG, central gray; SNc, substantia nigra pars compacta; PN, pontine raphe nuclei.

in $\mathrm{AD}$ and $\mathrm{HD}$ murine models and $\mathrm{PD}$ cellular models, beneficial effects of PACAP have been related to the increase of BDNF gene expression and protein levels (Rat et al., 2011; Brown et al., 2013, 2014; Cabezas-Llobet et al., 2018). Interestingly, some in vitro experiments have allowed the characterization of the molecular mechanisms involved. In rat cortical and hippocampal cultured neurons PACAPPAC1R stimulation induced BDNF transcription through the activation of AC/PKA signaling pathway (Yaka et al., 2003; Dong et al., 2010). AC/PKA together with MAPK is known to act through phosphorylation of cAMP response element-binding protein (CREB), which enhances BDNF signal transduction (Impey et al., 1998; Tao et al., 1998). Accordingly, PAC1R activation has been shown to enhance CREB phosphorylation and BDNF expression in in vitro and in vivo neurodegenerative models (Rat et al., 2011; Brown et al., 2013; Cabezas-Llobet et al., 2018). Therefore, BDNF enhanced expression has been proposed to be a key mechanism underlying neuroprotection and cognitive improvement induced by PACAP-PAC1R stimulation.

It has also been described that the capacity of PACAP-PAC1R to induce BDNF can be exerted through the glutamatergic $\mathrm{N}$ methyl-D-aspartate (NMDA) receptor. NMDA receptors play an essential role in synaptic plasticity and synaptogenesis (Nicoll and Malenka, 1999). Dysregulation of NMDA receptors activity is associated with cognitive impairment in $\mathrm{AD}$ (Avila et al.,
2017), PD (Vanle et al., 2018), and HD (Giralt et al., 2012) among others. Because their function is regulated by different cell modifications, the effect of PAC1R signaling on NMDA receptors activity has been studied. In cortical and hippocampal neurons PAC1R activation potentiates NMDA receptors, which induces BDNF expression (Pellegri et al., 1998; Yaka et al., 2003; Dong et al., 2010). It is described that NMDA receptors activation can promote the synthesis and release of BDNF (Marini et al., 1998). Therefore, PACAP/PAC1R has been proposed to regulate NMDA receptor activity promoting a trophic activity through the action of BDNF. Importantly, PAC1R related signaling can also activate directly the BDNF Tyrosine kinase B (TrkB) receptor, as observed in primary cultures of hippocampal neurons (Lee et al., 2002). Altogether, these results strongly suggest that PACAP-PAC1R enhances in a direct and/or indirect manner BDNF expression and trophic signaling responsible for neuroprotection, synaptic plasticity, and cognitive improvement (Figure 3).

PAC1R activation has also been shown to promote proliferation in neurogenic adult brain regions. This fact is interesting because, in the early stages of many neurodegenerative diseases, such as $\mathrm{AD}, \mathrm{HD}$, and $\mathrm{PD}$, adult neurogenesis decreases, which is associated with non-motor symptoms such as memory impairment and cognitive decline (Winner et al., 2011). In adult mice, PAC1R stimulation was found to enhance the proliferation in lateral ventricle and dentate 


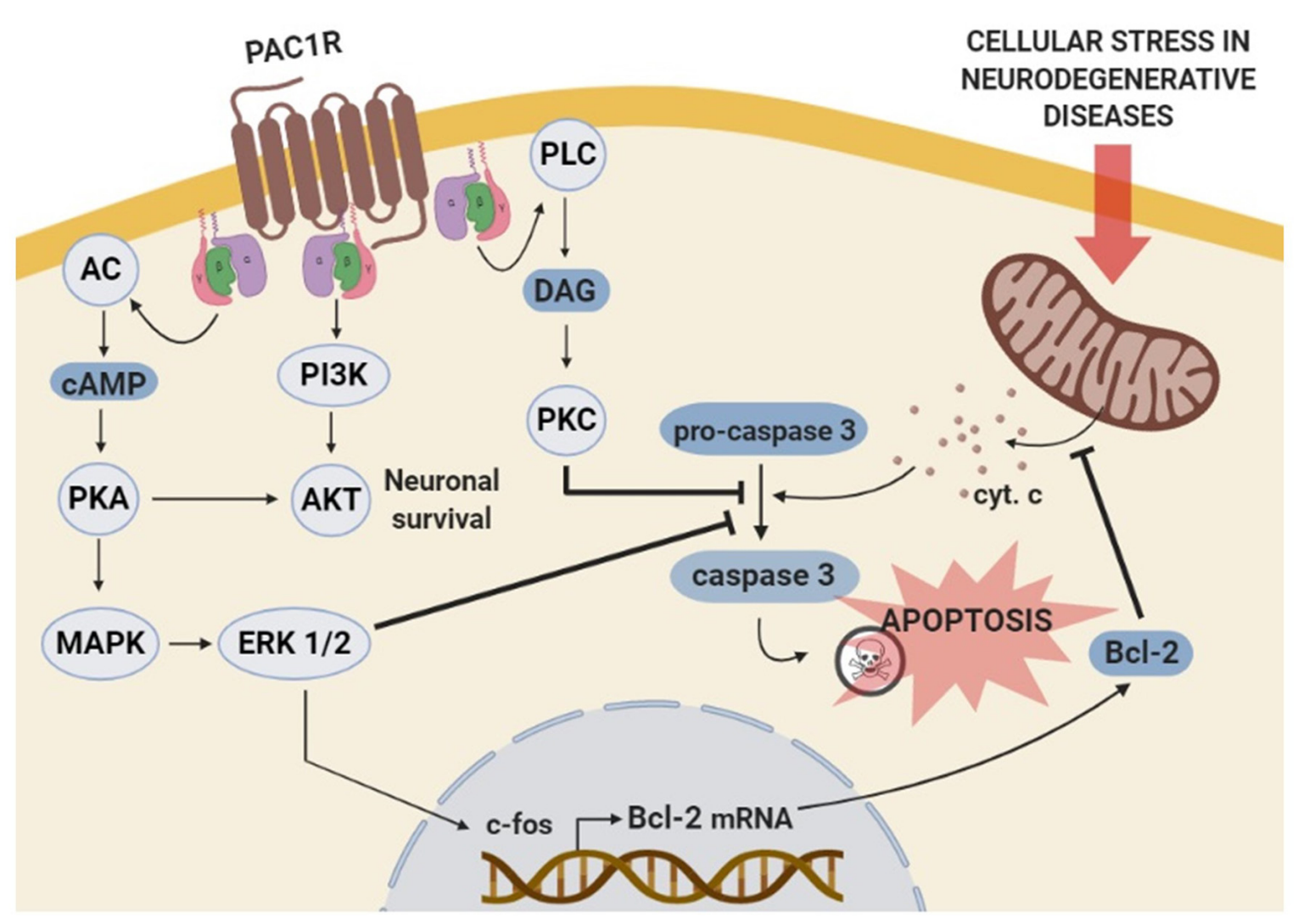

FIGURE 2 | Schematic representation of the molecular mechanisms involved in PAC1R mediated anti-apoptotic effect. The stimulation of PAC1R activates protein kinase A (PKA) cascade signaling, leading to extracellular signal-regulated kinase (ERK) phosphorylation. Activated ERK induces the transcription of neuroprotective genes such as c-fos and Bcl-2, which finally inhibits the mitochondrial apoptotic pathway and blocks pro-caspase-3 activation. The inhibitory effect of the PACAP-PAC1R system on pro-caspase-3 cleavage can be induced via additional phosoholipase C (PLC)/protein kinase C (PKC) pathway. Moreover, PAC1R can also activate phosphatidylinositol 3 kinase (PI3K)/Akt system and promote neuronal survival to counteract the apoptotic process.

gyrus of the hippocampus, two neurogenic regions sensitive to neurodegeneration. The authors defined PKA as the principal signaling pathway involved (Mercer et al., 2004). In contrast, in immature cerebellar granule cells, PAC1R was suggested to inhibit proliferation via the AC/PKA pathway (Obara et al., 2007) responsible for the increase of Lot-1 expression (Contestabile et al., 2005; Fila et al., 2009). In cerebellar granule cells, PC12, and neuroblastoma cells, PAC1R activation promotes differentiation with neurite initiation and elongation (Deutsch et al., 1993; Hernandez et al., 1995; Gonzalez et al., 1997). Results of these studies point out an AC dependent but PKA independent signaling pathway in this action (Deutsch et al., 1993; Hernandez et al., 1995; Ravni et al., 2006, 2008). Moreover, a specific analysis of the transduction pathways involved in cell differentiation induced by PACAP concluded that PKC is not implicated (Vaudry et al., 1998). Downstream AC, PACAP would activate ras-proximate-1 (Rap1) and MAPK to induce early growth response protein 1 (Egr1) expression and in turn neuroblast differentiation (Ravni et al., 2008). The ability of PACAP to promote dendritic spine remodeling in cultured hippocampal neurons is mediated among others by the disintegrin and metalloproteinase 10 (ADAM10; Gardoni et al., 2012) and the
microRNA-132 upregulation (Hayata-Takano et al., 2019). Taken together, these results indicate that, PAC1R activation coupled to AC and their downstream transduction pathways (Ravni et al., 2006) are determinant for the control of neuroblast proliferation and differentiation in brain regions affected by neurodegenerative diseases.

\section{Neuroprotective Actions Related to VPAC1R and VPAC2R}

\section{VPAC Receptors in Neurogenesis and Synaptic Function}

VPAC receptors are considered dynamic regulators of postnatal and adult hippocampal neurogenesis by regulating survival, proliferation, and differentiation of precursor cells in the CNS. It has been shown that VPAC2R maintains stem cells population by supporting their survival and preventing neuronal or glial differentiation. In contrast, VPAC1R activation has been found to promote neurogenic granule cell fate (Zaben et al., 2009). Interestingly, both VPAC receptors were demonstrated to be determinant for the synaptic function in the hippocampus (Cunha-Reis et al., 2005). The activity of VPAC receptors 


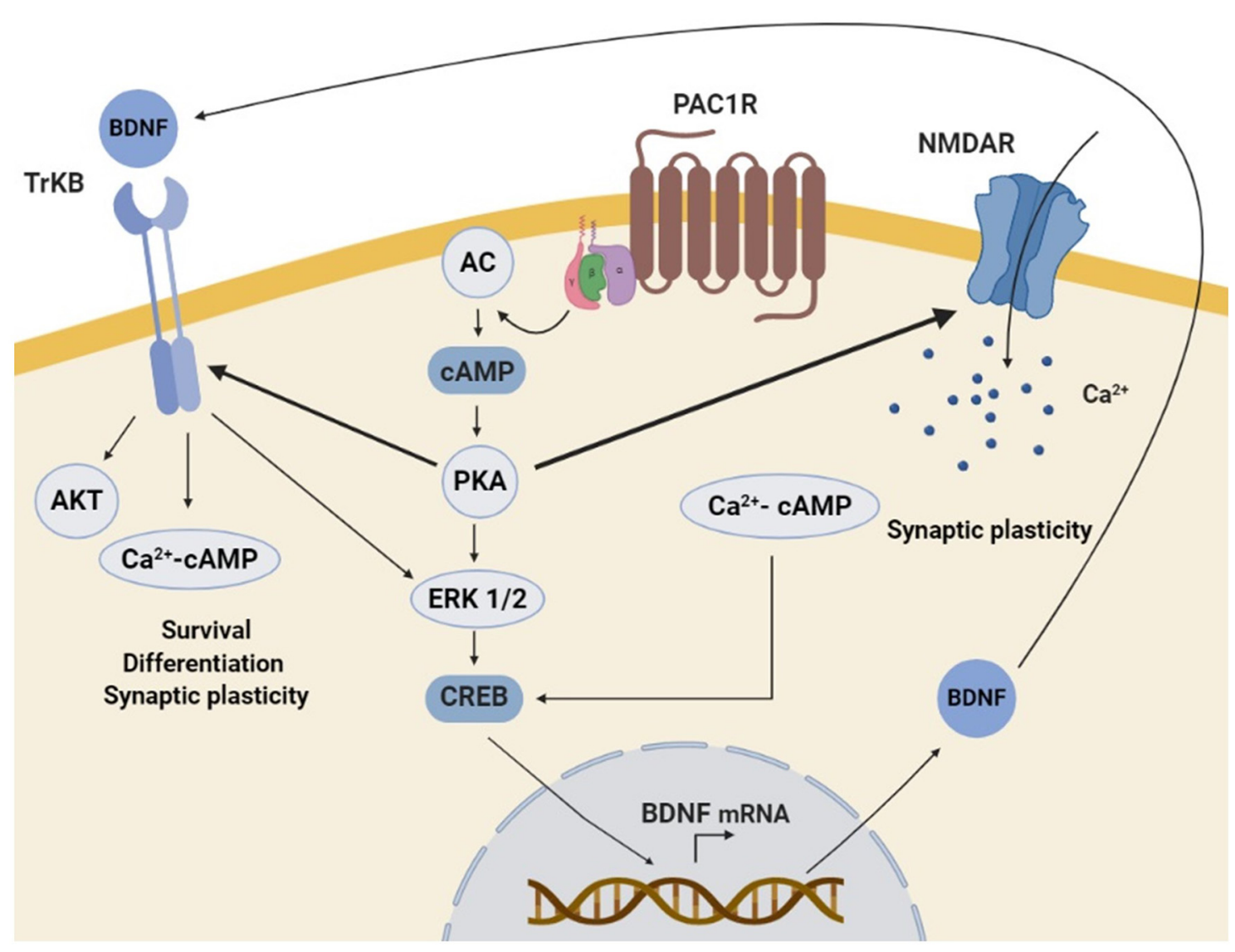

FIGURE 3 | Schematic representation of the molecular mechanisms involved in PAC1R mediated neurotrophic effect. The stimulation of PAC1R by PACAP activates the protein kinase $\mathrm{A}$ (PKA) signaling pathway, which can potentiate N-methyl-D-aspartate (NMDA) receptors and/or induce downstream the phosphorylation of extracellular signal-regulated kinase (ERK). In both cases, CAMP response element-binding protein (CREB) is activated and enhances brain-derived neurotrophic factor (BDNF) transcription. Increased BDNF protein levels activate the TrkB receptor, which can also be potentiated by PKA. Finally, TrkB associated trophic signaling pathways promote neuronal survival, differentiation, and synaptic plasticity.

has been associated with the PKA signaling pathway (Vaudry et al., 2000b) which leads to ERK activation, which finally promotes cell proliferation and/or differentiation (Langer, 2012). Moreover, the VPAC1R-mediated synaptic plasticity in the hippocampus is specifically mediated through the PKC pathway (Cunha-Reis et al., 2005).

\section{VPAC Receptors in Glia Mediated Effects}

Although some authors have found VIP direct effect in neurons, there is increasing evidence that most neuroprotective actions promoted by VPAC receptors in neurodegenerative diseases involve glial cells.

In astrocytes, it has been demonstrated that VPAC receptors activation induces the secretion of neurotrophic and neuroprotective factors (Figure 4). For instance, activitydependent neuroprotective protein (ADNP) and activitydependent neurotrophic factor (ADNF) are released after VPAC receptors stimulation from astrocytes (Brenneman and Gozes, 1996; Bassan et al., 1999). ADNP and ADNF regulate brain development and promote neuronal survival and plasticity (Brenneman and Gozes, 1996; Gozes and SpivakPohis, 2006). Importantly, these functions are mainly related to their most active fragments, NAP (NAPVSIPQ) and ADNF-9 (SALLRSIPA), respectively, which are demonstrated to be neuroprotective against multiple toxins in vitro (Gozes et al., 2003; Lagrèze et al., 2005; Smith-Swintosky et al., 2005). For instance, both ADNF9 and NAP protect against dopamine and 6-OHDA toxicity in PC12 and neuroblastoma cell models of PD (Offen et al., 2000). Interestingly, VIP-stimulated astrocytes can also secret neurotrophin-3 (Brenneman et al., 1997, 2003; Dejda et al., 2005). Specific involvement of VPAC1R and VPAC2R in astrocyte-mediated neuroprotection has been poorly studied, but some results suggest that VPAC2R plays the main key role. It has been found that VIP/VPAC2R system is neuroprotective by promoting the release of $\mathrm{ADNP}$ and BDNF in cultured astrocytes (Zusev and Gozes, 2004; Passemard et al., 2011). Moreover, the increased expression of glutamate transporters associated with reactive astrocytes could prevent cultured neurons against excitotoxicity (Nishimoto et al., 2011). Importantly, astrocytic-dependent neuroprotection has been 


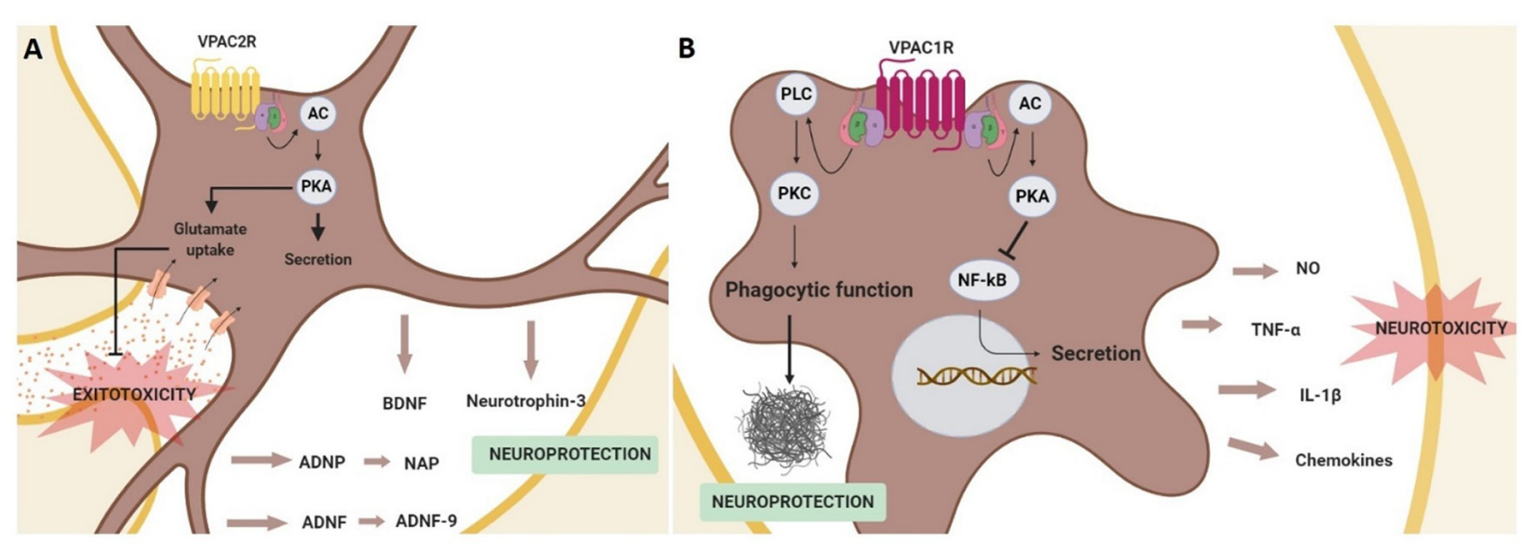

FIGURE 4 | Schematic representation of neuroprotective effects mediated by the activation of the VPAC receptors in glial cells. In astrocytes (A) VPAC2R activation promotes the secretion of neurotrophic and neuroprotective factors, in addition to prevent neurons from excitotoxicity by enhancing the glutamate re-uptake in astrocytes. These actions are associated with adenylyl cyclase (AC)/protein kinase A (PKA) activation. In microglia (B) the stimulation of VPAC1R inhibits the secretion of pro-inflammatory agents through the activation of the PKA signaling pathway and protects against $\beta$-amyloid fibrils enhancing the microglia phagocytic function via protein kinase $\mathrm{C}(\mathrm{PKC})$ activation.

related to the cAMP/PKA pathway (Nishimoto et al., 2011; Passemard et al., 2011; Figure 4).

It has also been described that VIP can regulate the release of proinflammatory cytokines from microglia. This action of VIP on microglial cells has been studied in neurodegenerative diseases, as excessive microglial activation contributes to the physiopathology of $\mathrm{AD}, \mathrm{PD}$, and $\mathrm{HD}$, among others (Subhramanyam et al., 2019). In AD and PD models, it has been shown that VIP exerts a neuroprotective effect through the inhibition of tumor necrosis factor- $\alpha(\mathrm{TNF} \alpha)$, interleukin $1 \beta$ (IL-1 $\beta$ ), nitric oxide (NO) and different chemokines release (Delgado, 2002; Delgado and Ganea, 2003; Delgado et al., 2008; Song et al., 2012). Importantly, this VIP effect has been related specifically to VPAC1R activation coupled to the cAMP/PKA pathway and associated to the inhibition of NF- $\kappa \mathrm{B}$ activation, a transcription factor of several genes encoding neurotoxic mediators (Delgado, 2002; Delgado and Ganea, 2003; Delgado et al., 2008). Interestingly, in a AD in vivo model, VPAC1R stimulation also enhances microglial phagocytosis of fibrillar beta-amyloid, but in this case through the activation of the PKC pathway (Song et al., 2012; Figure 4).

Even if the above information suggests a key role of VPAC receptors coupled to the $\mathrm{CAMP} / \mathrm{PKA}$ pathway in the regulation of adult neurogenesis most of the actual investigations are restricted to their function during development of the SNC. Consequently, more studies are needed to clarify and understand the contribution of VPAC receptors in the context of cognitive dysfunction in neurodegenerative diseases. Currently, it is considered that in the context of neurodegenerative diseases, the VIP-VPACR system exerts its neuroprotective action mainly indirectly through astroglial and microglial cells. In astrocytes, VPAC2R has a key role in promoting the secretion of different neuroprotective and neurotrophic factors, besides preventing from glutamate excitotoxicity. On the other hand, VPAC1R in microglia acts as an inflammatory mediator and protects against $\beta$-amyloid fibrils.

\section{DESIGNING PACAP AND VIP SYNTHETIC DERIVATES TO IMPROVE THE THERAPEUTIC ACTIVITY IN NEURODEGENERATIVE DISEASES}

The therapeutic application of PACAP and VIP neuropeptides for the treatment of neurodegenerative diseases shows some limitations. Importantly, both neuropeptides are susceptible to be rapidly degraded. In humans, PACAP38 isoform has a plasma half-life of less than 5-10 min (Ramos-Álvarez et al., 2015) while VIP shows a plasmatic half-life of approximately 1 min (Domschke et al., 1978). Additionally, the widespread distribution of PACAP/VIP receptors in the CNS and the peripheral tissues can cause many side effects. Therefore, recent developed synthetic analogs showing increased plasmatic half-life and displaying receptor selectivity have been proposed as therapeutic agents.

PACAP is metabolized mainly by dipeptidyl peptidase IV (DPP IV; Zhu et al., 2003), which promotes the formation of dipeptides from the N-terminus (Mentlein, 1999). As the PACAP amino-terminal domain is essential for the activation of its receptors (Gourlet et al., 1996), the cleavage by DPP IV suppresses PACAP biological activity (Gourlet et al., 1996). Moreover, PACAP can also be cleaved by endopeptidases, that recognize two dibasic pairs (Arg14-Lys15 and Lys20-Lys21), and carboxypeptidases, which action depends on the C-terminal segment (Bourgault et al., 2009). Therefore, chemical strategies aimed to modify the putative DPP IV, endopeptidase, and carboxypeptidase sites of cleavage offer the possibility to obtain more stable PACAP-analogues. For instance, the addition of an acetyl or hexanoyl group at the $\mathrm{N}$-terminus and the inversion 
of chirality of the Ser residue in position 2 are known to offer stability to PACAP by completely suppressing the action of DPP IV (Bourgault et al., 2008). Additionally, different amino acids have been determined as crucial for the specific binding of PACAP to its receptors, including His1, Asp3, and Phe6 (Lamine et al., 2016). As PACAP neuroprotective effects are mainly related to PAC1R, it has been proposed synthetic PAC1R agonists as interesting therapeutic molecules (Ramos-Álvarez et al., 2015). The Acetyl-[Ala15, Ala20] PACAP38 propylamine was designed to be a potent PAC1R agonist, in addition, to be more metabolically stable than native PACAP (Bourgault et al., 2008). Recently, the effects of this analog on memory and post-learning BDNF expression have been studied in Wistar rats. Surprisingly, the administration of acetyl-(Ala15, Ala20) PACAP38-propyl amide did not improve the cognitive function of rats, and accordingly, did not induce BDNF expression (Ladjimi et al., 2019). However, the authors showed that this analog could increase the activity of antioxidative enzymes in the neocortex of rats (Ladjimi et al., 2019). Unfortunately, the effect of acetyl-(Ala15, Ala20) PACAP38-propyl amide has not been tested in neurodegenerative models. The Ac-[Phe(pI)6, Nle17] PACAP (1-27) is another analog designed to specifically activate PAC1R/VPAC1R without affinity to VPAC2R. This is important because the activation of VPAC2R is associated with peripheral side effects such as vasodilation, an increase of heart rate, and water retention (Warren et al., 1992; Tsutsumi et al., 2002; Farnham et al., 2012). Interestingly, Ac-[Phe(pI)6, Nle17] PACAP (1-27) presents resistance against dipeptidyl peptidase IV activity, increasing its stability in human plasma (Lamine et al., 2016). This analog protects from $\mathrm{MPP}^{+}$-induced toxicity and appeared to be as efficient as PACAP (Lamine et al., 2016). Moreover, it was found to exert reduced cardiovascular side effects after treatment in an in vivo model of PD. However, the capacity of Ac-[Phe(pI)6, Nle17] PACAP (1-27) analog on cognitive deficits in neurodegenerative models has not been evaluated yet. Shorter fragments such as the amidated PACAP23 have shown their neuroprotective action in vitro (Lamine et al., 2019) but it remains to investigate if they keep their activity in vivo, in particular after intranasal injection. Indeed, the $\mathrm{C}$ terminal part of PACAP seems to be important for its transportation across the blood-brain barrier (Banks et al., 2006). Thereby, novel PACAP-TAT peptide with enhanced ability to cross biological barriers (Yu et al., 2012) and gH625liposomes (Iachetta et al., 2019) may help to deliver PACAP derivatives to the brain.

\section{REFERENCES}

Alzheimer's Association. (2015). Alzheimer's association report: 2015 Alzheimer's disease facts and figures. Alzheimers Dement. 11, 332-384. doi: 10.1016/j.jalz. 2015.02.003

Andersen, O., Fahrenkrug, J., Wikkelsø, C., and Johansson, B. B. (1984). VIP in cerebrospinal fluid of patients with multiple sclerosis. Peptides 5, 435-437. doi: 10.1016/0196-9781(84)90249-3

Arai, H., Moroji, T., and Kosaka, K. (1984). Somatostatin and vasoactive intestinal polypeptide in postmortem brains from patients with Alzheimer-type dementia. Neurosci. Lett. 52, 73-78. doi: 10.1016/0304-3940(84)90353-7
Regarding VIP, its susceptibility to endopeptidases is also well known (Deng and Jin, 2017). To overcome this metabolic limitation, the addition of an $\mathrm{N}$-terminal stearic acid (lipophilic) to different VIP short fragments was tested. The sequence stearyl-Lys-Lys-Tyr-Leu-NH2 (stearyl-KKYL-NH2) was found to have higher stability than VIP, providing the main neurotrophic and neuroprotective actions of the peptide (Gozes et al., 1999). Moreover, replacing the methionine in position 17 with a norleucine (Nle), resulted in a superactive VIP analog. Named stearyl-Nle17-VIP (SNV), it is 100-fold more potent than VIP in promoting neuronal survival, acting at femtomolar-picomolar concentrations in rat cerebral cortical cultures (Gozes et al., 1995; Ashur-Fabian et al., 1999). Interestingly, the beneficial effects of SNV in cognitive function have been tested in vivo. Using two rat models of developmental retardation, water maze experiments showed that SNV improves cognitive functions (Gozes et al., 1998). Similarly, chronic treatment with SNV was demonstrated to improve learning and memory functions in ethylcholine aziridium treated animals (Gozes et al., 1996) and in an apolipoprotein E (ApoE) deficient mice (Gozes et al., 1997), used as models of AD. For its part, the VPAC2R agonist D-p-Cl-Ac-Phe(pI)6, Leu17-VIP slows the pathogenesis of PD through modulation of the inflammatory response (Olson et al., 2015).

Altogether, several analogues more stable and selective than PACAP and VIP have been designed to increase the therapeutic activity and applicability. However, their role in cognitive dysfunction in neurodegenerative diseases is poorly known. Therefore, further research and some clinical trials are needed to ensure the therapeutic potential of these promising analogs.

\section{AUTHOR CONTRIBUTIONS}

IS-T, NC-L, and XX wrote the manuscript. IS-T, DV, and XX revised the literature. Supervision and conceptualization was performed by DV and XX. Editing was performed by XX.

\section{FUNDING}

This work was supported by the University of Girona (MPCUdG2016/036), INSERM (U1239), Rouen Normandy University, Normandy Region, and the European Union. Europe gets involved in Normandy with the European Regional Development Fund (ERDF).

Ashur-Fabian, O., Giladi, E., Brenneman, D. E., and Gozes, I. (1997) Identification of VIP/PACAP receptors on rat astrocytes using antisense oligodeoxynucleotides. J. Mol. Neurosci. 9, 211-222. doi: 10.1007/bf02800503

Ashur-Fabian, O., Perl, O., Lilling, G., Fridkin, M., and Gozes, I. (1999). SNV, a lipophilic superactive VIP analog, acts through cGMP to promote neuronal survival. Peptides 20, 629-633. doi: 10.1016/s0196-9781(99)00017-0

Aubert, N., Falluel-Morel, A., Vaudry, D., Xifro, X., Rodriguez-Alvarez, J., Fisch, C., et al. (2006). PACAP and C2-ceramide generate different AP-1 complexes through a MAP-kinase-dependent pathway: involvement of c-Fos in PACAP-induced Bcl-2 expression. J. Neurochem. 99, 1237-1250. doi: 10.1111/j. 1471-4159.2006.04148.x 
Avila, J., Llorens-Martín, M., Pallas-Bazarra, N., Bolós, M., Perea, J. R., RodríguezMatellán, A., et al. (2017). Cognitive decline in neuronal aging and Alzheimer's disease: role of NMDA receptors and associated proteins. Front. Neurosci. 11:626. doi: 10.3389/fnins.2017.00626

Bahdoudi, S., Ghouili, I., Hmiden, M., do Rego, J. L., Lefranc, B., Leprince, J., et al. (2018). Neuroprotective effects of the gliopeptide ODN in an in vivo model of Parkinson's disease. Cell. Mol. Life Sci. 75, 2075-2091. doi: 10.1007/s00018-0172727-2

Banks, W. A., Uchida, D., Arimura, A., Somagyvári-Vigh, A., and Shioda, S. (2006). Transport of pituitary adenylate cyclase-activating polypeptide across the blood-brain barrier and the prevention of ischemia-induced death of hippocampal neurons. Ann. N Y Acad. Sci. 805, 270-277. doi: 10.1111/j.17496632.1996.tb17489.x

Baranowska-Bik, A., Kochanowski, J., Uchman, D., Wolinska-Witort, E., Kalisz, M., Martynska, L., et al. (2013). Vasoactive intestinal peptide (VIP) and pituitary adenylate cyclase activating polypeptide (PACAP) in humans with multiple sclerosis. J. Neuroimmunol. 263, 159-161. doi: 10.1016/j.jneuroim. 2013.08.012

Basille, M., Vaudry, D., Coulouarn, Y., Jegou, S., Lihrmann, I., Fournier, A., et al. (2000). Comparative disribution of pituitary adenylate cyclase-activating polypeptide (PACAP) binding sites and PACAP receptor MRNAs in the rat brain during development. J. Comp. Neurol. 425, 495-509. doi: 10.1002/10969861(20001002)425:4<495::aid-cne3>3.0.co;2-a

Bassan, M., Zamostiano, R., Davidson, A., Pinhasov, A., Giladi, E., Perl, O., et al. (1999). Complete sequence of a novel protein containing a femtomolaractivity- dependent neuroprotective peptide. J. Neurochem. 72, 1283-1293. doi: 10.1046/j.1471-4159.1999.0721283.x

Bathina, S., and Das, U. N. (2015). Brain-derived neurotrophic factor and its clinical Implications. Arch. Med. Sci. 11, 1164-1178. doi: 10.5114/aoms.2015. 56342

Benbrika, S., Desgranges, B., Eustache, F., and Viader, F. (2019). Cognitive, emotional and psychological manifestations in amyotrophic lateral sclerosis at baseline and overtime: a review. Front. Neurosci. 13:951. doi: 10.3389/fnins. 2019.00951

Bezard, E., Gross, C. E., and Brotchie, J. M. (2003). Presymptomatic compensation in Parkinson's disease is not dopamine-mediated. Trends Neurosci. 26, 215-221. doi: 10.1016/S0166-2236(03)00038-9

Bhave, S. V., and Hoffman, P. L. (2003). Phosphatidylinositol 3/-OH kinase and protein kinase A pathways mediate the anti-apoptotic effect of pituitary adenylyl cyclase-activating polypeptide in cultured cerebellar granule neurons: modulation by ethanol. J. Neurochem. 88, 359-369. doi: 10.1046/j.1471-4159. 2003.02167.x

Bonaventura, G., Iemmolo, R., D’Amico, A. G., La Cognata, V., Costanzo, E., Zappia, M., et al. (2018). PACAP and PAC1R are differentially expressed in motor cortex of amyotrophic lateral sclerosis patients and support survival of iPSC-derived motor neurons. J. Cell. Physiol. 233, 3343-3351. doi: 10.1002/jcp. 26182

Botia, B., Seyer, D., Ravni, A., Bénard, M., Falluel-Morel, A., Cosette, P., et al. (2008). Peroxiredoxin 2 is involved in the neuroprotective effects of PACAP in cultured cerebellar granule neurons. J. Mol. Neurosci. 36, 61-72. doi: 10.1007/s12031-008-9075-5

Bourgault, S., Vaudry, D., Botia, B., Couvineau, A., Laburthe, M., Vaudry, H., et al. (2008). Novel stable PACAP analogs with potent activity towards the PAC1 receptor. Peptides 29, 919-932. doi: 10.1016/j.peptides.2008. 01.022

Bourgault, S., Vaudry, D., Dejda, A., Doan, N. D., Vaudry, H., and Fournier, A. (2009). Pituitary adenylate cyclase-activating polypeptide: focus on structureactivity relationships of a neuroprotective peptide. Curr. Med. Chem. 16, 4462-4480. doi: 10.2174/092986709789712899

Bramham, C. R., and Messaoudi, E. (2005). BDNF function in adult synaptic plasticity: the synaptic consolidation hypothesis. Prog. Neurobiol. 76, 99-125. doi: 10.1016/j.pneurobio.2005.06.003

Brenneman, D. E., and Gozes, I. (1996). A femtomolar-acting neuroprotective peptide. J. Clin. Invest. 97, 2299-2307. doi: 10.1172/jci118672

Brenneman, D. E., Phillips, T. M., Festoff, B. W., and Gozes, I. (1997). Identity of neurotrophic molecules released from astroglia by vasoactive intestinal peptide. Ann. N Y Acad. Sci. 814, 167-173. doi: 10.1111/j.1749-6632.1997. tb46155.x
Brenneman, D. E., Phillips, T. M., Hauser, J., Hill, J. M., Spong, C. Y., and Gozes, I. (2003). Complex array of cytokines released by vasoactive intestinal peptide. Neuropeptides 37, 111-119. doi: 10.1016/s0143-4179(03)00022-2

Brown, D., Tamas, A., Reglödi, D., and Tizabi, Y. (2013). PACAP protects against salsolinol-induced toxicity in dopaminergic SH-SY5Y cells: implication for Parkinson's disease. J. Mol. Neurosci. 50, 600-607. doi: 10.1007/s12031-0130015-7

Brown, D., Tamas, A., Reglodi, D., and Tizabi, Y. (2014). PACAP protects against inflammatory-mediated toxicity in dopaminergic SH-SY5Y cells: implication for Parkinson's disease. Neurotox. Res. 26, 230-239. doi: 10.1007/s12640-0149468-X

Brück, A., Kurki, T., Kaasinen, V., Vahlberg, T., and Rinne, J. O. (2004). Hippocampal and prefrontal atrophy in patients with early non-demented Parkinson's disease is related to cognitive impairment. J. Neurol. Neurosurg. Psychiatry 75, 1467-1469. doi: 10.1136/jnnp.2003.031237

Cabezas-Llobet, N., Vidal-Sancho, L., Masana, M., Fournier, A., Alberch, J., Vaudry, D., et al. (2018). Pituitary adenylate cyclase-activating polypeptide (PACAP) enhances hippocampal synaptic plasticity and improves memory performance in Huntington's disease. Mol. Neurobiol. 55, 8263-8277. doi: 10.1007/s12035-018-0972-5

Caviness, J. N., Driver-Dunckley, E., and Connor, D. J. (2007). Defining mild cognitive impairment in Parkinson's disease. Focus Park. Dis. 19, 15-18. doi: $10.1002 / \mathrm{mds} .21453$

Chaudhury, D., Loh, D. H., Dragich, J. M., Hagopian, A., and Colwell, C. S. (2008). Select cognitive deficits in Vasoactive Intestinal Peptide deficient mice. $B M C$ Neurosci. 9:63. doi: 10.1186/1471-2202-9-63

Chiaravalloti, N. D., and DeLuca, J. (2008). Cognitive impairment in multiple sclerosis. Lancet Neurol. 7, 1139-1151. doi: 10.1016/S1474-4422(08)70259-X

Chung, C. Y., Seo, H., Sonntag, K. C., Brooks, A., Lin, L., and Isacson, O. (2005). Cell type-specific gene expression of midbrain dopaminergic neurons reveals molecules involved in their vulnerability and protection. Hum. Mol. Genet. 14, 1709-1725. doi: 10.1093/hmg/ddi178

Ciranna, L., and Cavallaro, S. (2003). Opposing effects by pituitary adenylate cyclase-activating polypeptide and vasoactive intestinal peptide on hippocampal synaptic transmission. Exp. Neurol. 184, 778-784. doi: 10.1016/s0014-4886(03)00300-5

Cohen-Cory, S., Kidane, A. H., Shirkey, N. J., and Marshak, S. (2010). Brainderived neurotrophic factor and the development of structural neuronal connectivity. Dev. Neurobiol. 70, 271-288. doi: 10.1002/dneu.20774

Contestabile, A., Fila, T., Bartesaghi, R., and Ciani, E. (2005). Cyclic AMP-mediated regulation of transcription factor Lot1 expression in cerebellar granule cells. J. Biol. Chem. 280, 33541-33551. doi: 10.1074/jbc.m413323200

Cunha-Reis, D., Ribeiro, J. A., and Sebastião, A. M. (2005). VIP enhances synaptic transmission to hippocampal CA1 pyramidal cells through activation of both VPAC1 and VPAC2 receptors. Brain Res. 1049, 52-60. doi: 10.1016/j.brainres. 2005.04.077

Deguil, J., Chavant, F., Lafay-Chebassier, C., Pérault-Pochat, M. C., Fauconneau, B., and Pain, S. (2010). Neuroprotective effect of PACAP on translational control alteration and cognitive decline in MPTP Parkinsonian mice. Neurotox. Res. 17, 142-155. doi: 10.1007/s12640-009-9091-4

Dejda, A., Chan, P., Seaborn, T., Coquet, L., Jouenne, T., Fournier, A., et al. (2010). Involvement of stathmin 1 in the neurotrophic effects of PACAP in PC12 cells. J. Neurochem. 114, 1498-1510. doi: 10.1111/j.1471-4159.2010. 06873.x

Dejda, A., Sokoowska, P., and Nowak, J. Z. (2005). Neuroprotective potential of three neuropeptides PACAP, VIP and PHI. Pharmacol. Reports 57, $307-320$.

Delgado, M. (2002). Vasoactive intestinal peptide and pituitary adenylate cyclaseactivating polypeptide inhibit CBP-NF-кB interaction in activated microglia. Biochem. Biophys. Res. Commun. 297, 1181-1185. doi: 10.1016/s0006$291 \times(02) 02305-7$

Delgado, M., and Ganea, D. (2003). Neuroprotective effect of vasoactive intestinal peptide (VIP) in a mouse model of Parkinson's disease by blocking microglial activation. FASEB J. 17, 944-946. doi: 10.1096/fj.02-0799fje

Delgado, M., Varela, N., and Gonzalez-Rey, E. (2008). Vasoactive intestinal peptide protects against $\beta$-amyloid-induced neurodegeneration by inhibiting microglia activation at multiple levels. Glia 56, 1091-1103. doi: 10.1002/glia. 20681 
Deng, G., and Jin, L. (2017). The effects of vasoactive intestinal peptide in neurodegenerative disorders. Neurol. Res. 39, 65-72. doi: 10.1080/01616412. 2016.1250458

Deutsch, P. J., Schadlow, V. C., and Barzilai, N. (1993). 38-Amino acid form of pituitary adenylate cyclase activating peptide induces process outgrowth in human neuroblastoma cells. J. Neurosci. Res. 35, 312-320. doi: 10.1002/jnr. 490350311

Dickson, L., and Finlayson, K. (2009). VPAC and PAC receptors: from ligands to function. Pharmacol. Ther. 121, 294-316. doi: 10.1016/j.pharmthera.2008. 11.006

Dogrukol-Ak, D., Kumar, V. B., Ryerse, J. S., Farr, S. A., Verma, S., Nonaka, N., et al. (2009). Isolation of peptide transport system- 6 from brain endothelial cells: therapeutic effects with antisense inhibition in Alzheimer and stroke models. J. Cereb. Blood Flow Metab. 29, 411-422. doi: 10.1038/jcbfm.2008.131

Domschke, S., Domschke, W., Bloom, S. R., Mitznegg, P., Mitchell, S. J., Lux, G., et al. (1978). Vasoactive intestinal peptide in man: pharmacokinetics, metabolic and circulatory effects. Gut 19, 1049-1053. doi: 10.1136/gut.19.11.1049

Dong, Y. X., Fukuchi, M., Inoue, M., Takasaki, I., Tabuchi, A., Wu, C. F., et al. (2010). Pituitary adenylate cyclase-activating polypeptide (PACAP) is an upstream regulator of prodynorphin mRNA expression in neurons. Neurosci. Lett. 484, 174-177. doi: 10.1016/j.neulet.2010.08.044

Emson, P. C., Fahrenkrug, J., and Spokes, E. G. S. (1979). Vasoactive intestinal polypeptide (VIP): distribution in normal human brain and in Huntington's disease. Brain Res. 173, 174-178. doi: 10.1016/0006-8993(79)91109-0

Fahrenkrug, J., Popovic, N., Georg, B., Brundin, P., and Hannibal, J. (2007). Decreased VIP and VPAC2 receptor expression in the biological clock of the R6/2 Huntington's disease mous. J. Mol. Neurosci. 31, 139-180. doi: 10.1385/jmn/31:02:139

Falluel-Morel, A., Aubert, N., Vaudry, D., Basille, M., Fontaine, M., Fournier, A., et al. (2004). Opposite regulation of the mitochondrial apoptotic pathway by C2-ceramide and PACAP through a MAP-kinase-dependent mechanism in cerebellar granule cells. J. Neurochem. 91, 1231-1243. doi: 10.1111/j.1471-4159. 2004.02810.x

Farnham, M. M. J., Lung, M. S. Y., Tallapragada, V. J., and Pilowsky, P. M. (2012). PACAP causes PAC 1/VPAC 2 receptor mediated hypertension and sympathoexcitation in normal and hypertensive rats. Am. J. Physiol. Hear. Circ. Physiol. 303, H910-H917. doi: 10.1152/ajpheart.00464.2012

Feher, M., Gaszner, B., Tamas, A., Gil-Martinez, A. L., Fernandez-Villalba, E., Herrero, M. T., et al. (2018). Alteration of the PAC1 receptor expression in the basal ganglia of MPTP-induced parkinsonian macaque monkeys. Neurotox. Res. 33, 702-715. doi: 10.1007/s12640-017-9841-7

Fernandez-Martin, A., Gonzalez-Rey, E., Chorny, A., Martin, J., Pozo, D., Ganea, D., et al. (2006). VIP prevents experimental multiple sclerosis by downregulating both inflammatory and autoimmune components of the disease. Ann. N Y Acad. Sci. 1070, 276-281. doi: 10.1196/annals.1317.026

Ferrier, I. N., Cross, A. J., Johnson, J. A., Robert, G. W., Crow, T. J., Corsellis, Y. C., et al. (1983). Neuropeptides in Alzheimer type dementia. J. Neurol. Sci. 62, 159-170. doi: 10.1016/0022-510x(83)90196-x

Fila, T., Trazzi, S., Crochemore, C., Bartesaghi, R., and Ciani, E. (2009). Lot1 is a key element of the pituitary adenylate cyclase-activating polypeptide (PACAP)/cyclic AMP pathway that negatively regulates neuronal precursor proliferation. J. Biol. Chem. 284, 15325-15338. doi: 10.1074/jbc.M109.002329

Gardoni, F., Saraceno, C., Malinverno, M., Marcello, E., Verpelli, C., Sala, C., et al. (2012). The neuropeptide PACAP38 induces dendritic spine remodeling through ADAM10-N-cadherin signaling pathway. J. Cell Sci. 125, 1401-1406. doi: $10.1242 /$ jcs.097576

Giralt, A., Saavedra, A., Alberch, J., and Pérez-Navarro, E. (2012). Cognitive dysfunction in Huntington's disease: humans, mouse models and molecular mechanisms. J. Huntingtons Dis. 1, 155-173. doi: 10.3233/JHD-120023

Gonzalez, B. J., Basille, M., Vaudry, D., Fournier, A., and Vaudry, H. (1997). Pituitary adenylate cyclase-activating polypeptide promotes cell survival and neurite outgrowth in rat cerebellar neuroblasts. Neuroscience 78, 419-430. doi: 10.1016/s0306-4522(96)00617-3

Gourlet, P., Vandermeers, A., Vandermeers-Piret, M. C., Rathé, J., De Neef, P., and Robberecht, P. (1996). C-terminally shortened pituitary adenylate cyclase-activating peptides (PACAP) discriminate PACAP I, PACAP II-VIP1 and PACAP II-VIP2 recombinant receptors. Regul. Pept. 62, 125-130. doi: 10.1016/0167-0115(96)00010-9
Goursaud, S., Schäfer, S., Dumont, A. O., Vergouts, M., Gallo, A., Desmet, N., et al. (2015). The anti-inflammatory peptide stearyl-norleucine-VIP delays disease onset and extends survival in a rat model of inherited amyotrophic lateral sclerosis. Exp. Neurol. 263, 91-101. doi: 10.1016/j.expneurol.2014.09.022

Gozes, I., and Spivak-Pohis, I. (2006). Neurotrophic effects of the peptide NAP: a novel neuroprotective drug candidate. Curr. Alzheimer Res. 3, 197-199. doi: 10.2174/156720506777632790

Gozes, I., Bachar, M., Bardea, A., Davidson, A., Rubinraut, S., and Fridkin, M. (1998). Protection against developmental deficiencies by a lipophilic VIP analogue. Neurochem. Res. 23, 689-693. doi: 10.1023/a:1022494907001

Gozes, I., Bachar, M., Bardea, A., Davidson, A., Rubinraut, S., Fridkin, M., et al. (1997). Protection against developmental retardation in apolipoprotein E- deficient mice by a fatty neuropeptide: implications for early treatment of Alzheimer's disease. J. Neurobiol. 33, 329-342. doi: 10.1002/(sici)10974695(199709)33:3<329::aid-neu10>3.0.c0;2-a

Gozes, I., Bardea, A., Reshef, A., Zamostiano, R., Zhukovsky, S., Rubinraut, S., et al. (1996). Neuroprotective strategy for Alzheimer disease: intranasal administration of a fatty neuropeptide. Proc. Natl. Acad. Sci. US A 93, 427-432. doi: 10.1073/pnas.93.1.427

Gozes, I., Divinsky, I., Pilzer, I., Fridkin, M., Brenneman, D. E., and Spier, A. D. (2003). From vasoactive intestinal peptide (VIP) through activity-dependent neuroprotective protein (ADNP) to NAP: a view of neuroprotection and cell division. J. Mol. Neurosci. 20, 315-322. doi: 10.1385/jmn:20:3:315

Gozes, I., Lilling, G., Glazer, R., Ticher, A., Ashkenazi, I., Davidson, A., et al. (1995). Superactive lipophilic peptides discriminate multiple vasoactive intestinal peptide receptors. J. Pharmacol. Exp. Ther. 273, 161-167.

Gozes, I., Perl, O., Giladi, E., Davidson, A., Ashur-Fabian, O., Rubinraut, S., et al. (1999). Mapping the active site in vasoactive intestinal peptide to a core of four amino acids: neuroprotective drug design. Proc. Natl. Acad. Sci. U S A 96, 4143-4148. doi: 10.1073/pnas.96.7.4143

Grimaldi, M., and Cavallaro, S. (1999). Functional and molecular diversity of PACAP/VIP receptors in cortical neurons and type I astrocytes. Eur. J. Neurosci. 11, 2767-2772. doi: 10.1046/j.1460-9568.1999.00693.x

Hajji, K., Mteyrek, A., Sun, J., Cassar, M., Mezghani, S., Leprince, J., et al. (2019). Neuroprotective effects of PACAP against paraquat-induced oxidative stress in the Drosophila central nervous system. Hum. Mol. Genet. 28, 1905-1918. doi: 10.1093/hmg/ddz031

Han, P., Caselli, R. J., Baxter, L., Serrano, G., Yin, J., Beach, T. G., et al. (2015) Association of pituitary adenylate cyclase-activating polypeptide with cognitive decline in mild cognitive impairment due to Alzheimer disease. JAMA Neurol. 72, 333-339. doi: 10.1001/jamaneurol.2014.3625

Han, P., and Lucero, M. T. (2006). Pituitary adenylate cyclase activating polypeptide reduces expression of Kv1.4 and Kv4.2 subunits underlying A-type $\mathrm{K}^{+}$current in adult mouse olfactory neuroepithelia. Neuroscience 138, 411-419. doi: 10.1016/j.neuroscience.2005.11.028

Han, P., Liang, W., Baxter, L. C., Yin, J., Tang, Z., Beach, T. G., et al. (2014a). Pituitary adenylate cyclase-activating polypeptide is reduced in Alzheimer disease. Neurology 82, 1724-1728. doi: 10.1212/WNL.0000000000000417

Han, P., Tang, Z., Yin, J., Maalouf, M., Beach, T. G., Reiman, E. M., et al. (2014b). Pituitary adenylate cyclase-activating polypeptide protects against $\beta$-amyloid toxicity. Neurobiol. Aging 35, 2064-2071. doi: 10.1016/j.neurobiolaging.2014. 03.022

Harmar, A. J., Fahrenkrug, J., Gozes, I., Laburthe, M., May, V., Pisegna, J. R., et al. (2012). Pharmacology and functions of receptors for vasoactive intestinal peptide and pituitary adenylate cyclase-activating polypeptide: IUPHAR review 1. Br. J. Pharmacol. 166, 4-17. doi: 10.1111/j.1476-5381.2012.01871.x

Hashimoto, H., Nogi, H., Mori, K., Ohishi, H., Shigemoto, R., Yamamoto, K., et al. (1996). Distribution of the mRNA for a pituitary adenylate cyclase-activating polypeptide receptor in the rat brain: an in situ hybridization study. J. Comp. Neurol. 371, 567-577. doi: 10.1002/(SICI)10969861(19960805)371:4<567::AID-CNE6>3.0.CO;2-2

Hayata-Takano, A., Kamo, T., Kijima, H., Seiriki, K., Ogata, K., Ago, Y., et al. (2019). Pituitary adenylate cyclase-activating polypeptide modulates dendritic spine maturation and morphogenesis via microRNA-132 upregulation. J. Neurosci. 39, 4208-4220. doi: 10.1523/JNEUROSCI.2468-18.2019

Hernandez, A., Kimball, B., Romanchuk, G., and Mulholland, M. W. (1995). Pituitary adenylate cyclase-activating peptide stimulates neurite growth in PC12 cells. Peptides 16, 927-932. doi: 10.1016/0196-9781(95)00059-s 
Hou, Y., Dan, X., Babbar, M., Wei, Y., Hasselbach, S. G., Croteau, D. L., et al. (2019). Ageing as a risk factor for neurodegenerative disease. Nat. Rev. Neurol. 15, 565-581. doi: 10.1038/s41582-019-0244-7

Iachetta, G., Falanga, A., Molino, Y., Masse, M., Jabès, F., Mechioukhi, Y., et al. (2019). gH625-liposomes as tool for pituitary adenylate cyclase-activating polypeptide brain delivery. Sci. Rep. 9:9183. doi: 10.1038/s41598-019-45137-8

Impey, S., Obrietan, K., Wong, S. T., Poser, S., Yano, S., Wayman, G., et al. (1998). Cross talk between ERK and PKA is required for $\mathrm{Ca}^{2+}$ stimulation of CREB-dependent transcription and ERK nuclear translocation. Neuron 21, 869-883. doi: 10.1016/s0896-6273(00)80602-9

Jégou, S., Javoy-Agid, F., Delbende, C., Tranchand-Bunel, D., Coy, D. H., Agid, Y., et al. (1988). Regional distribution of vasoactive intestinal peptide in brains from normal and parkinsonian subjects. Peptides 9, 787-793. doi: 10.1016/0196-9781(88)90123-4

Jolivel, V., Basille, M., Aubert, N., de Jouffrey, S., Ancian, P., Le Bigot, J. F., et al. (2009). Distribution and functional characterization of pituitary adenylate cyclase-activating polypeptide receptors in the brain of non-human primates. Neuroscience 160, 434-451. doi: 10.1016/j.neuroscience.2009.02.028

Joo, K. M., Chung, Y. H., Kim, M. K., Nam, R. H., Lee, B. L., Lee, K. H., et al. (2004). Distribution of vasoactive intestinal peptide and pituitary adenylate cyclaseactivating polypeptide receptors (VPAC 1 , VPAC 2, and PAC 1 receptor) in the rat brain. J. Comp. Neurol. 476, 388-413. doi: 10.1002/cne.20231

Kaddour, H., Hamdi, Y., Vaudry, D., Basille, M., Desrues, L., Leprince, J., et al. (2013). The octadecaneuropeptide ODN prevents 6-hydroxydopamineinduced apoptosis of cerebellar granule neurons through a PKC-MAPKdependent pathway. J. Neurochem. 125, 620-633. doi: 10.1111/jnc.12140

Kalia, L. V., and Lang, A. E. (2015). Parkinson's disease. Lancet 386, 896-912. doi: 10.1016/S0140-6736(14)61393-3

Kato, H., Ito, A., Kawanokuchi, J., Jin, S., Mizuno, T., Ojika, K., et al. (2004). Pituitary adenylate cyclase-activating polypeptide (PACAP) ameliorates experimental autoimmune encephalomyelitis by suppressing the functions of antigen presenting cells. Mult. Scler. 10, 651-659. doi: 10.1191/1352458504ms1096oa

Korkmaz, O. T., and Tunçel, N. (2019). Advantages of vasoactive intestinal peptide for the future treatment of Parkinson's disease. Curr. Pharm. Des. 24, 4693-4701. doi: 10.2174/1381612825666190111150953

Korkmaz, O. T., Ay, H., Aytan, N., Carreras, I., Kowall, N. W., Dedeoglu, A., et al. (2019). Vasoactive intestinal peptide decreases $\beta$-amyloid accumulation and prevents brain atrophy in the 5xFAD mouse model of Alzheimer's disease. J. Mol. Neurosci. 68, 389-396. doi: 10.1007/s12031-018-1226-8

Korkmaz, O. T., Ay, H., Ulupinar, E., and Tunçel, N. (2012). Vasoactive intestinal peptide enhances striatal plasticity and prevents dopaminergic cell loss in parkinsonian rats. J. Mol. Neurosci. 48, 565-573. doi: 10.1007/s12031-0129781-x

Ladjimi, M. H., Barbouche, R., Ben Barka, Z., Vaudry, D., Lefranc, B., Leprince, J., et al. (2019). Comparison of the effects of PACAP-38 and its analog, acetyl$\left[\mathrm{Ala}^{15}, \mathrm{Ala}^{20}\right]$ PACAP-38-propylamide, on spatial memory, post-learning BDNF expression and oxidative stress in rat. Behav. Brain Res. 359, 247-257. doi: 10.1016/j.bbr.2018.10.023

Lagrèze, W. A., Pielen, A., Steingart, R., Schlunck, G., Hofmann, H. D., Gozes, I., et al. (2005). The peptides ADNF-9 and NAP increase survival and neurite outgrowth of rat retinal ganglion cells in vitro. Investig. Ophthalmol. Vis. Sci. 46, 933-938. doi: 10.1167/iovs.04-0766

Lamine, A., Létourneau, M., Doan, N. D., Maucotel, J., Couvineau, A., Vaudry, H., et al. (2016). Characterizations of a synthetic pituitary adenylate cyclaseactivating polypeptide analog displaying potent neuroprotective activity and reduced in vivo cardiovascular side effects in a Parkinson's disease model. Neuropharmacology 108, 440-450. doi: 10.106/j.neuropharm.2015. 05.014

Lamine, A., Poujol de Molliens, M., Létourneau, M., Hébert, T. E., Vaudry, D., Fournier, A., et al. (2019). The amidated PACAP ${ }_{1-23}$ fragment is a potent reduced-size neuroprotective agent. Biochim. Biophys. Acta 1863:129410. doi: 10.1016/j.bbagen.2019.08.003

Lamine-Ajili, A., Fahmy, A. M., Létourneau, M., Chatenet, D., Labonté, P., Vaudry, D., et al. (2016). Effect of the pituitary adenylate cyclase-activating polypeptide on the autophagic activation observed in in vitro and in vivo models of Parkinson's disease. Biochim. Biophys. Acta 1862, 688-695. doi: 10.1016/j.bbadis.2016.01.005
Langer, I. (2012). Mechanisms involved in VPAC receptors activation and regulation: lessons from pharmacological and mutagenesis studies. Front. Endocrinol. 3:129. doi: 10.3389/fendo.2012.00129

Lee, F. S., Rajagopal, R., Kim, A. H., Chang, P. C., and Chao, M. V. (2002). Activation of Trk neurotrophin receptor signaling by pituitary adenylate cyclase-activating polypeptides. J. Biol. Chem. 277, 9096-9102. doi: 10.1074/jbc. m107421200

Maasz, G., Zrinyi, Z., Reglodi, D., Petrovics, D., Rivnyak, A., Kiss, T., et al. (2017). Pituitary adenylate cyclase-activating polypeptide (PACAP) has a neuroprotective function in dopamine-based neurodegeneration in rat and snail parkinsonian models. DMM Dis. Model. Mech. 10, 127-139. doi: 10.1242/dmm.027185

MacDonald, M. E., Ambrose, C. M., Duyao, M. P., Myers, R. H., Lin, C., Srinidhi, L., et al. (1993). A novel gene containing a trinucleotide repeat that is expanded and unstable on Huntington's disease chromosomes. Cell 72, 971-983. doi: 10.1016/0092-8674(93)90585-e

Marini, A. M., Rabin, S. J., Lipsky, R. H., and Mocchetti, I. (1998). Activity-dependent release of brain-derived neurotrophic factor underlies the neuroprotective effect of N-methyl-D-aspartate. J. Biol. Chem. 273, 29394-29399. doi: 10.1074/jbc.273.45.29394

Masmoudi, O., Gandolfo, P., Leprince, J., Vaudry, D., Fournier, A., PatteMensah, C., et al. (2003). Pituitary adenylate cyclase-activating polypeptide (PACAP) stimulates endozepine release from cultured rat astrocytes via a PKA-dependent mechanism. FASEB J. 17, 17-27. doi: 10.1096/fj.02-0317com

Masuo, Y., Matsumoto, Y., Tokito, F., Tsuda, M., and Fujino, M. (1993). Effects of vasoactive intestinal polypeptide (VIP) and pituitary adenylate cyclase activating polypeptide (PACAP) on the spontaneous release of acetylcholine from the rat hippocampus by brain microdialysis. Brain Res. 611, 207-215. doi: 10.1016/0006-8993(93)90504-g

Mentlein, R. (1999). Dipeptidyl-peptidase IV (CD26)-role in the inactivation of regulatory peptides. Regul. Pept. 85, 9-24. doi: 10.1016/s0167-0115(99)00089-0

Mercer, A., Rönnholm, H., Holmberg, J., Lundh, H., Heidrich, J., Zachrisson, O., et al. (2004). PACAP promotes neural stem cell proliferation in adult mouse brain. J. Neurosci. Res. 76, 205-215. doi: 10.1002/jnr.20038

Nicoll, R. A., and Malenka, R. C. (1999). Expression mechanisms underlying NMDA receptor-dependent long-term potentiation. Ann. N Y Acad. Sci. 868, 515-525. doi: 10.1111/j.1749-6632.1999.tb11320.x

Niedzielska, E., Smaga, I., Gawlik, M., Moniczewski, A., Stankowicz, P., Pera, J., et al. (2016). Oxidative stress in neurodegenerative diseases. Mol. Neurobiol. 53, 4094-4125. doi: 10.1007/s12035-015-9337-5

Nishimoto, M., Miyakawa, H., Wada, K., and Furuta, A. (2011). Activation of the VIP/VPAC2 system induces reactive astrocytosis associated with increased expression of glutamate transporters. Brain Res. 1383, 43-53. doi: 10.1016/j. brainres.2011.01.082

Nomura, M., Ueta, Y., Serino, R., Kabashima, N., Shibuya, I., and Yamashita, H. (1996). PACAP type I receptor gene expression in the paraventricular and supraoptic nuclei of rats. Neuroreport 8, 67-70. doi: 10.1097/00001756199612200-00014

Nonaka, N., Banks, W. A., Mizushima, H., Shioda, S., and Morley, J. E. (2002). Regional differences in PACAP transport across the blood-brain barrier in mice: a possible influence of strain, amyloid $\beta$ protein and age. Peptides 23, 2197-2202. doi: 10.1016/s0196-9781(02)00248-6

Nonaka, N., Farr, S. A., Nakamachi, T., Morley, J. E., Nakamura, M., Shioda, S., et al. (2012). Intranasal administration of PACAP: uptake by brain and regional brain targeting with cyclodextrins. Peptides 36, 168-175. doi: 10.1016/j. peptides.2012.05.021

Obara, Y., Horgan, A. M., and Stork, P. J. S. (2007). The requirement of Ras and Rap1 for the activation of ERKs by cAMP, PACAP, and $\mathrm{KCl}$ in cerebellar granule cells. J. Neurochem. 101, 470-482. doi: 10.1111/j.1471-4159.2006. 04390.x

Offen, D., Sherki, Y., Melamed, E., Fridkin, M., Brenneman, D. E., and Gozes, I. (2000). Vasoactive intestinal peptide (VIP) prevents neurotoxicity in neuronal cultures: relevance to neuroprotection in Parkinson's disease. Brain Res. 854, 257-262. doi: 10.1016/s0006-8993(99)02375-6

Olson, K. E., Kosloski-Bilek, L. M., Anderson, K. M., Diggs, B. J., Clark, B. E., Gledhill, J. M., et al. (2015). Selective VIP receptor agonists facilitate immune transformation for dopaminergic neuroprotection in MPTP-intoxicated mice. J. Neurosci. 35, 16463-16478. doi: 10.1523/jneurosci.2131-15.2015 
Onoue, S., Endo, K., Ohshima, K., and Yajima, T. (2002). The neuropeptide PACAP attenuates $\beta$-amyloid (1-42)-induced toxicity in PC12 cells. Peptides 23, 1471-1478. doi: 10.1016/s0196-9781(02)00085-2

Passemard, S., Sokolowska, P., Schwendimann, L., and Gressens, P. (2011). VIPinduced neuroprotection of the developing brain. Curr. Pharm. Des. 17, 1036-1039. doi: 10.2174/138161211795589409

Pellegri, G., Magistretti, P. J., and Martin, J. L. (1998). VIP and PACAP potentiate the action of glutamate on BDNF expression in mouse cortical neurones. Eur. J. Neurosci. 10, 272-280. doi: 10.1046/j.1460-9568.1998. 00052.x

Rai, S. N., Dilnashin, H., Birla, H., Singh, S. S., Zahra, W., Rathore, A. S., et al. (2019). The role of PI3K/Akt and ERK in neurodegenerative disorders. Neurotox. Res. 35, 775-795. doi: 10.1007/s12640-019-0003-y

Ramos-Álvarez, I., Mantey, S. A., Nakamura, T., Nuche-Berenguer, B., Moreno, P., Moody, T. W., et al. (2015). A structure-function study of PACAP using conformationally restricted analogs: identification of $\mathrm{PAC} 1$ receptor-selective PACAP agonists. Peptides 66, 26-42. doi: 10.1016/j.peptides.2015.01.009

Raoult, E., Roussel, B. D., Bénard, M., Lefebvre, T., Ravni, A., Ali, C., et al. (2011). Pituitary adenylate cyclase-activating polypeptide (PACAP) stimulates the expression and the release of tissue plasminogen activator (tPA) in neuronal cells: involvement of tPA in the neuroprotective effect of PACAP. J. Neurochem. 119, 920-931. doi: 10.1111/j.1471-4159.2011.07486.x

Rat, D., Schmitt, U., Tippmann, F., Dewachter, I., Theunis, C., Wieczerzak, E., et al. (2011). Neuropeptide pituitary adenylate cyclase-activating polypeptide (PACAP) slows down Alzheimer's disease-like pathology in amyloid precursor protein-transgenic mice. FASEB J. 25, 3208-3218. doi: 10.1096/fj.10-180133

Ravni, A., Bourgault, S., Lebon, A., Chan, P., Galas, L., Fournier, A., et al. (2006). The neurotrophic effects of PACAP in PC12 cells: control by multiple transduction pathways. J. Neurochem. 98, 321-329. doi: 10.1111/j.1471-4159. 2006.03884.x

Ravni, A., Vaudry, D., Gerdin, M. J., Eiden, M. V., Falluel-Morel, A., Gonzalez, B. J., et al. (2008). A cAMP-dependent, protein kinase A-independent signaling pathway mediating neuritogenesis through Egr1 in PC12 cells. Mol. Pharmacol. 73, 1688-1708. doi: 10.1124/mol.107.044792

Reglodi, D., Lubics, A., Tamás, A., Szalontay, L., and Lengvári, I. (2004a). Pituitary adenylate cyclase activating polypeptide protects dopaminergic neurons and improves behavioral deficits in a rat model of Parkinson's disease. Behav. Brain Res. 151, 303-312. doi: 10.1016/j.bbr.2003.09.007

Reglodi, D., Tamás, A., Lubics, A., Szalontay, L., and Lengvári, I. (2004b). Morphological and functional effects of PACAP in 6-hydroxydopamineinduced lesion of the substantia nigra in rats. Regul. Pept. 123, 85-94. doi: 10.1016/j.regpep.2004.05.016

Reglodi, D., Renaud, J., Tamas, A., Tizabi, Y., Socías, S. B., Del-Bel, E., et al. (2017). Novel tactics for neuroprotection in Parkinson's disease: role of antibiotics, polyphenols and neuropeptides. Prog. Neurobiol. 155, 120-148. doi: 10.1016/j. pneurobio.2015.10.004

Reglodi, D., Tamas, A., Jungling, A., Vaczy, A., Rivnyak, A., Fulop, B. D., et al. (2018). Protective effects of pituitary adenylate cyclase activating polypeptide against neurotoxic agents. Neurotoxicology 66, 185-194. doi: 10.1016/j.neuro. 2018.03.010

Sawamoto, N., Honda, M., Hanakawa, T., Aso, T., Inoue, M., Toyoda, H., et al. (2007). Cognitive slowing in Parkinson disease is accompanied by hypofunctioning of the striatum. Neurology 68, 1062-1068. doi: 10.1212/01. wnl.0000257821.28992.db

Seaborn, T., Masmoudi-Kouli, O., Fournier, A., Vaudry, H., and Vaudry, D. (2011). Protective effects of pituitary adenylate cyclase-activating polypeptide (PACAP) against apoptosis. Curr. Pharm. Des. 17, 204-214. doi: $10.2174 / 138161211795049679$

Seaborn, T., Ravni, A., Au, R., Chow, B. K. C., Fournier, A., Wurtz, O., et al. (2014). Induction of serpinbla by PACAP or NGF is required for PC12 cells survival after serum withdrawal. J. Neurochem. 131, 21-32. doi: 10.1111/jnc.12780

Shibasaki, Y., Hayata-Takano, A., Hazama, K., Nakazawa, T., Shintani, N., Kasai, A., et al. (2015). Atomoxetine reverses locomotor hyperactivity, impaired novel object recognition and prepulse inhibition impairment in mice lacking pituitary adenylate cyclase-activating polypeptide. Neuroscience 297, 95-104. doi: 10.1016/j.neuroscience.2015.03.062

Shioda, S., Nakai, Y., Nakajo, S., Nakaya, K., and Arimura, A. (1996). Pituitary adenylate cyclase-activating polypeptide and its type I receptors in the rat hypothalamus: neuroendocrine interactionsa. Ann. N Y Acad. Sci. 805, 670-676. doi: 10.1111/j.1749-6632.1996.tb17539.x

Smith-Swintosky, V. L., Gozes, I., Brenneman, D. E., D’Andrea, M. R., and PlataSalaman, C. R. (2005). Activity-dependent neurotrophic factor-9 and NAP promote neurite outgrowth in rat hippocampal and cortical cultures. J. Mol. Neurosci. 25, 225-237. doi: 10.1385/jmn:25:3:225

Song, M., Xiong, J., Wang, Y., Tang, J., Zhang, B., and Bai, Y. (2012). VIP enhances phagocytosis of fibrillar $\beta$-amyloid by microglia and attenuates amyloid deposition in the brain of APP/PS1 mice. PLoS One 7:e29790. doi: 10.1371/journal.pone.0029790

Staines, D. R. (2008). Are multiple sclerosis and amyotrophic lateral sclerosis autoimmune disorders of endogenous vasoactive neuropeptides? Med. Hypotheses 70, 413-418. doi: 10.1016/j.mehy.2007.04.038

Stranahan, A. M. (2011). Physiological variability in brain-derived neurotrophic factor expression predicts dendritic spine density in the mouse dentate gyrus. Neurosci. Lett. 495, 60-62. doi: 10.1016/j.neulet.2011.03.037

Subhramanyam, C. S., Wang, C., Hu, Q., and Dheen, S. T. (2019). Microgliamediated neuroinflammation in neurodegenerative diseases. Semin. Cell Dev. Biol. 94, 112-120. doi: 10.1016/j.semcdb.2019.05.004

Takei, N., Skoglösa, Y., and Lindholm, D. (1998). Neurotrophic and neuroprotective effects of pituitary adenylate cyclase- activating polypeptide (PACAP) on mesencephalic dopaminergic neurons. J. Neurosci. Res. 54, 698-706. doi: 10.1002/(sici)1097-4547(19981201)54:5<698::aid-jnr15>3.0. co;2-5

Tamás, A., Lubics, A., Lengvári, I., and Reglódi, D. (2006). Protective effects of PACAP in excitotoxic striatal lesion. Ann. N Y Acad. Sci. 1070, 570-574. doi: 10.1196/annals.1317.083

Tan, Y. V., Abad, C., Lopez, R., Dong, H., Liu, S., Lee, A., et al. (2009). Pituitary adenylyl cyclase-activating polypeptide is an intrinsic regulator of treg abundance and protects against experimental autoimmune encephalomyelitis. Proc. Natl. Acad. Sci. U S A 106, 2012-2017. doi: 10.1073/pnas.0812257106

Tan, Y. V., Abad, C., Wang, Y., Lopez, R., and Waschek, J. A. (2013). Pituitary adenylate cyclase activating peptide deficient mice exhibit impaired thymic and extrathymic regulatory T cell proliferation during EAE. PLoS One 8:e61200. doi: 10.1371/journal.pone.0061200

Tao, X., Finkbeiner, S., Arnold, D. B., Shaywitz, A. J., and Greenberg, M. E. (1998) $\mathrm{Ca} 2+$ influx regulates BDNF transcription by a CREB family transcription factor-dependent mechanism. Neuron 20, 709-726. doi: 10.1016/s08966273(00)81010-7

Tsutsumi, M., Claus, T. H., Liang, Y., Li, Y., Yang, L., Zhu, J., et al. (2002). A potent and highly selective VPAC2 agonist enhances glucose-induced insulin release and glucose disposal: a potential therapy for type 2 diabetes. Diabetes 51, 1453-1460. doi: 10.2337/diabetes.51.5.1453

Tunçel, N., Korkmaz, O. T., Tekin, N., Şener, E., Akyüz, F., and Inal, M. (2012). Antioxidant and anti-apoptotic activity of Vasoactive Intestinal Peptide (VIP) against 6-hydroxy dopamine toxicity in the rat corpus striatum. J. Mol. Neurosci. 46, 51-57. doi: 10.1007/s12031-011-9618-Z

Tunçel, N., Şener, E., Cerit, C., Karasu, U., Gürer, F., Şahintürk, V., et al. (2005). Brain mast cells and therapeutic potential of vasoactive intestinal peptide in a Parkinson's disease model in rats: Brain microdialysis, behavior and microscopy. Peptides 26, 827-836. doi: 10.1016/j.peptides.2004.12.019

Turi, G. F., Li, W. K., Chavlis, S., Pandi, I., O’Hare, J., Priestley, J. B., et al. (2019). Vasoactive intestinal polypeptide-expressing interneurons in the hippocampus support goal-oriented spatial learning. Neuron 101, 1150.e8-1165.e8. doi: 10.1016/j.neuron.2019.01.009

Ureshino, R. P., Erustes, A. G., Bassani, T. B., Wachilewski, P., Guarache, G. C., Nascimento, A. C., et al. (2019). The interplay between Ca2+ signaling pathways and neurodegeneration. Int. J. Mol. Sci. 20:6004. doi: 10.3390/ijms20236004

Usdin, T. E. D. B., Bonner, T. O. M. I., and Mezey, R. V. A. (1994). Two receptors for vasoactive intestinal with similar and complementary. Endocrinology 135, 2662-2680. doi: 10.1210/endo.135.6.7988457

Vanle, B., Olcott, W., Jimenez, J., Bashmi, L., Danovitch, I., and Ishak, W. W. (2018). NMDA antagonists for treating the non-motor symptoms in Parkinson's disease. Transl. Psychiatry 8:117. doi: 10.1038/s41398-018-0162-2

Vaudry, D., Basille, M., Anouar, Y., Fournier, A., Vaudry, H., and Gonzalez, B. J. (1998). The neurotrophic activity of PACAP on rat cerebellar granule cells is associated with activation of the protein kinase A pathway and c-fos gene 
expression. Ann. N Y Acad. Sci. 865, 92-99. doi: 10.1111/j.1749-6632.1998. tb11167.x

Vaudry, D., Chen, Y., Ravni, A., Hamelink, C., Elkahloun, A. G., and Eiden, L. E. (2002a). Analysis of the PC12 cell transcriptome after differentiation with pituitary adenylate cyclase-activating polypeptide (PACAP). J. Neurochem. 83, 1272-1284. doi: 10.1046/j.1471-4159.2002.01242.x

Vaudry, D., Gonzalez, B. J., Basille, M., Yon, L., Fournier, A., and Vaudry, H. (2000b). Pituitary adenylate cyclase-activating polypeptide and its receptors: from structure to functions. Pharmacol. Rev. 52, 269-324. doi: 10.1046/j.14609568.2002.01981.x

Vaudry, D., Falluel-Morel, A., Bourgault, S., Basille, M., Burel, D., Wurtz, O., et al. (2009). Pituitary adenylate cyclase-activating polypeptide and its receptors: 20 Years after the discovery. Pharmacol. Rev. 61, 283-357. doi: 10.1124/pr.109. 001370

Vaudry, D., Gonzalez, B. J., Basille, M., Pamantung, T. F., Fontaine, M., Fournier, A., et al. (2000a). The neuroprotective effect of pituitary adenylate cyclase-activating polypeptide on cerebellar granule cells is mediated through inhibition of the CED3-related cysteine protease caspase-3/CPP32. Proc. Natl. Acad. Sci. U S A 97, 13390-13395. doi: 10.1073/pnas.97.24.13390

Vaudry, D., Pamantung, T. F., Basille, M., Rousselle, C., Fournier, A., Vaudry, H., et al. (2002b). PACAP protects cerebellar granule neurons against oxidative stress-induced apoptosis. Eur. J. Neurosci. 15, 1451-1460. doi: 10.1046/j.14609568.2002.01981.x

Vaudry, D., Rousselle, C., Basille, M., Falluel-Morel, A., Pamantung, T. F., Fontaine, M., et al. (2002c). Pituitary adenylate cyclase-activating polypeptide protects rat cerebellar granule neurons against ethanol-induced apoptotic cell death. Proc. Natl. Acad. Sci. U S A 99, 6398-6403. doi: 10.1073/pnas.082112699

Wang, G., Pan, J., Tan, Y. Y., Sun, X. K., Zhang, Y. F., Zhou, H. Y., et al. (2008). Neuroprotective effects of PACAP27 in mice model of Parkinson's disease involved in the modulation of KATP subunits and D2 receptors in the striatum. Neuropeptides 42, 267-276. doi: 10.1016/j.npep.2008.03.002

Wang, G., Qi, C., Fan, G. H., Zhou, H. Y., and Chen, S.-D. (2005). PACAP protects neuronal differentiated PC12 cells against the neurotoxicity induced by a mitochondrial complex I inhibitor, rotenone. FEBS Lett. 579, 4005-4011. doi: 10.1016/j.febslet.2005.06.013

Warren, J. B., Cockcroft, J. R., Larkin, S. W., Kajekar, R., Macrae, A., Ghatei, M. A., et al. (1992). Pituitary adenylate cyclase activating polypeptide is a potent vasodilator in humans. J. Cardiovasc. Pharmacol. 20, 83-87.

Watson, M. B., Nobuta, H., Abad, C., Lee, S. K., Bala, N., Zhu, C., et al. (2013). PACAP deficiency sensitizes nigrostriatal dopaminergic neurons to paraquatinduced damage and modulates central and peripheral inflammatory activation in mice. Neuroscience 240, 277-286. doi: 10.1016/j.neuroscience.2013.03.002

Werdelin, L., Gjerris, A., Boysen, G., Fahrenkrug, J., Jørgensen, O. S., and Rehfeld, J. F. (1989). Neuropeptides and neural cell adhesion molecule (NCAM) in CSF from patients with ALS. Acta Neurol. Scand. 79, 177-181. doi: 10.1111/j.1600-0404.1989.tb03735.x

Winner, B., Kohl, Z., and Gage, F. H. (2011). Neurodegenerative disease and adult neurogenesis. Eur. J. Neurosci. 33, 1139-1151. doi: 10.1111/j.1460-9568.2011. 07613.x

Wu, Z. L., Ciallella, J. R., Flood, D. G., O’Kane, T. M., Bozyczko-Coyne, D., and Savage, M. J. (2006). Comparative analysis of cortical gene expression in mouse models of Alzheimer's disease. Neurobiol. Aging 27, 377-386. doi: 10.1016/j. neurobiolaging.2005.02.010

Yaka, R., He, D. Y., Phamluong, K., and Ron, D. (2003). Pituitary adenylate cyclase-activating polypeptide (PACAP(1-38)) enhances N-methyl-Daspartate receptor function and brain-derived neurotrophic factor expression via RACK1. J. Biol. Chem. 278, 9630-9638. doi: 10.1074/jbc.M209141200

Yelkenli, I. H., Ulupinar, E., Korkmaz, O. T., Şener, E., Kuş, G., Filiz, Z., et al. (2016). Modulation of corpus striatal neurochemistry by astrocytes and vasoactive intestinal peptide (VIP) in Parkinsonian rats. J. Mol. Neurosci. 59, 280-289. doi: 10.1007/s12031-016-0757-0

Yu, R., Zeng, Z., Guo, X., Zhang, H. H., Liu, X., Ding, Y., et al. (2012). The TAT peptide endows PACAP with an enhanced ability to traverse bio-barriers. Neurosci. Lett. 527, 1-5. doi: 10.1016/j.neulet.2012.08.005

Zaben, M., Sheward, W. J., Shtaya, A., Abbosh, C., Harmar, A. J., Pringle, A. K., et al. (2009). The neurotransmitter VIP expands the pool of symmetrically dividing postnatal dentate gyrus precursors via VPAC2 receptors or directs them toward a neuronal fate via VPAC1 receptors. Stem Cells 27, 2539-2551. doi: $10.1002 /$ stem. 184

Zech, M., Roberts, G. W., Bogerts, B., Crow, T. J., and Polak, J. M. (1986). Neuropeptides in the amygdala of controls, schizophrenics and patients suffering from Huntington's chorea: an immunohistochemical study. Acta Neuropathol. 71, 259-266. doi: 10.1007/bf00688048

Zhou, C. J., Kikuyama, S., Shibanuma, M., Hirabayashi, T., Nakajo, S., Arimura, A., et al. (2000). Cellular distribution of the splice variants of the receptor for pituitary adenylate cyclase-activating polypeptide (PAC1-R) in the rat brain by in situ RT-PCR. Mol. Brain Res. 75, 150-158. doi: 10.1016/s0169328x(99)00300-9

Zhu, L., Tamvakopoulos, C., Xie, D., Dragovic, J., Shen, X., Fenyk-Melody, J. E., et al. (2003). The role of dipeptidyl peptidase IV in the cleavage of glucagon family peptides: in vivo metabolism of pituitary adenylate cyclase-activating polypeptide-(1-38). J. Biol. Chem. 278, 22418-22423. doi: 10.1074/jbc. M212355200

Zink, M., Otto, C., Zörner, B., Zacher, C., Schütz, G., Henn, F. A., et al. (2004). Reduced expression of brain-derived neurotrophic factor in mice deficient for pituitary adenylate cyclase activating polypeptide type-I-receptor. Neurosci. Lett. 360, 106-108. doi: 10.1016/j.neulet.2004.01.030

Zusev, M., and Gozes, I. (2004). Differential regulation of activity-dependent neuroprotective protein in rat astrocytes by VIP and PACAP. Regul. Pept. 123, 33-41. doi: 10.1016/j.regpep.2004.05.021

Conflict of Interest: The authors declare that the research was conducted in the absence of any commercial or financial relationships that could be construed as a potential conflict of interest.

Copyright (c) 2020 Solés-Tarrés, Cabezas-Llobet, Vaudry and Xifró. This is an open-access article distributed under the terms of the Creative Commons Attribution License (CC BY). The use, distribution or reproduction in other forums is permitted, provided the original author(s) and the copyright owner(s) are credited and that the original publication in this journal is cited, in accordance with accepted academic practice. No use, distribution or reproduction is permitted which does not comply with these terms. 